\title{
Experience, screening and syndication in venture capital investments
}

\author{
Catherine Casamatta ${ }^{1} \quad$ Carole Haritchabalet ${ }^{2}$
}

This version: february 2007

${ }^{1} \mathrm{CRG}$, University of Toulouse, and CEPR.

${ }^{2}$ GREMAQ, University of Toulouse.

Many thanks to Ulf Axelson, Bruno Biais, Denis Gromb, Bruno Jullien and Per Strömberg for their insights. The paper has also benefited from comments of participants at the Vth Toulouse Finance Workshop (2002), the Second Amsterdam Summer workshop in Corporate Finance Theory (2002), the Econometric Society European Meeting (2003), the SIFR Conference on Venture Capital and Entrepreneurial Finance (2003) and the GAEL-INRA seminar.

E-mail: catherine.casamatta@univ-tlse1.fr, carole.haritchabalet@univ-tlse1.fr. Corresponding address: Université de Toulouse I, Place Anatole France, 31042 Toulouse Cedex, France. 


\begin{abstract}
The objective of this paper is to understand why venture capitalists often syndicate their investments, and how syndication affects their post-investment involvement. We consider a venture capital investment model, in which the quality of investment projects is unknown. Depending on their level of experience, venture capitalists are more or less efficient at screening projects. Screening can also be improved by a second investor appraisal. Obtaining this second piece of information can be costly though, since the initial venture capitalist has to disclose the existence of the investment project to a second investor. The latter becomes de facto a potential competitor, reducing the initial venture capitalist's profits. In this setting, we first establish that syndication can be a coordination device to prevent competition. We then investigate how the syndication decision affects the screening process, and explore the cost of syndication in terms of investment decisions or post-investment involvement of venture capitalists. We conclude with empirical predictions linking the level of experience of venture capitalists, the decision to syndicate, the level of post-investment involvement and the characteristics of the venture capital investments.
\end{abstract}

Keywords: venture capital, syndication, screening, experience, competition.

JEL codes: G2, G3, D8. 


\section{Introduction}

Venture capitalists often look for financial partners to complete their investments in start-up firms. This so-called syndication can either take place at the same round of financing or be sequential, with new partners coming in at later rounds of financing. Even taken in the most restrictive sense, syndication is widely observed: Brander, Amit and Antweiler (2002) report from Canadian data that $60 \%$ of venture capital investments were syndicated in 1997 . Wright and Lockett (2003) report from VentureEconomics and EVCA data that about $30 \%$ of venture capital investments were syndicated in Europe in 2001, compared to $60 \%$ in the US. ${ }^{1}$ The objective of this paper is to understand why venture capitalists syndicate and how syndication affects the efficiency and the profitability of the venture capital industry.

At the root of these questions is the source of value-added of venture capitalists. Venture capital investments can be successful because venture capitalists are good at selecting projects and/or because they enhance the profitability of the projects they back by providing useful advice. Sahlman $(1988,1990)$ reports that venture capitalists spend a great deal of time to carefully select projects, and remain also deeply involved in the post-investment development of those projects. Emphasizing the importance of the selection process, Fenn, Liang and Prowse (1995) estimate that only $1 \%$ of the projects received by venture capitalists obtain financing. Gorman and Sahlman (1989) find that venture capitalists have repeated interactions with the firms they invest in. This enables them to extract information on the quality of their investment, in order to terminate the less promising ventures (Gompers (1995)). They can also monitor and directly control entrepreneurs (Lerner (1995), Hellmann and Puri (2002)), and provide managerial advice. $^{2}$

In line with the above empirical literature, we consider that the value added by venture capitalists is two-fold: their expertise allows them to spot the most profitable projects and to enhance their value by providing valuable advice. However, we do not view these two activities as separate tasks: the efficiency of the selection process determines the effectiveness of the venture capitalists' involvement. In our model, this interaction arises from the venture capitalist's effort being more valuable for high quality projects. Therefore, the decision to provide advice will depend on the perceived quality of the investment project. The important question is then: how can venture capitalists efficiently select projects? The answer we propose in this paper is that syndication helps to gather information on the investment opportunities, which improves the selection process, and impacts the post-investment involvement of venture capitalists.

\footnotetext{
${ }^{1}$ Hopp and Rieder (2006) document using German data that European figures are very sensitive to the industry considered: Biotech and Internet industries exhibit levels of syndication similar to their US counterparts.

${ }^{2}$ The importance of this advising role has been extensively documented empirically in Gorman and Sahlman (1989), Sahlman (1990), Bygrave and Timmons (1992), Gompers and Lerner (1999), and more recently Hellmann and Puri (2002). For theoretical treatments, see Schmidt (2003), Repullo and Suarez (1999), or Casamatta (2003).
} 
To study these issues, we consider a model where a venture capitalist must decide whether or not to invest in a highly uncertain project, and whether or not to exert costly effort to improve the project's profitability once investment is made. The venture capitalist can screen the project by generating an informative signal on the project's true quality. An important assumption is that the preciseness of his signal depends on his level of experience. On top of his signal, the venture capitalist has the opportunity to ask for a second evaluation, performed by another venture capitalist. However, obtaining this evaluation can be costly. Disclosing the existence of an investment opportunity to another venture capitalist makes him a potential rival: he could compete with the initial venture capitalist to obtain exclusive financing of the project. From the point of view of the venture capitalist first informed of a new project, revealing the existence of the project creates the conditions for profit-dissipating competition. In order to preserve part of his monopoly rents, the venture capitalist has no choice but to negotiate with his potential competitor, and share the project's surplus.

The main results of the model are the following. First, information can be gathered by forming a syndicate, i.e. by signing a co-investment, co-ownership contract between the two venture capitalists. Second, inexperienced venture capitalists do not fear potential competition because their evaluation of the project is not accurate enough to allow them to invest alone. They form a syndicate each time it is optimal to do so. At the opposite, very experienced venture capitalists suffer from potential competition and are more reluctant to syndicate. Therefore they need to choose more experienced partners or to forgo syndication. Third, syndication affects the venture capitalist's effort decision, to improve the project expected profitability. Moderately experienced venture capitalists do not exert enough effort, because of the cost of potential competition. At the opposite, very experienced venture capitalists exert too much effort, because of the same cost. The intuition of this result is the following. Potential competition prevents venture capitalists from gathering enough information. Consequently, moderately experienced venture capitalists who would like to, but cannot syndicate, remain too pessimistic about the project's success, and do not exert effort. At the opposite, very experienced venture capitalists remain too optimistic about the project's success and exert too much effort. Last, syndication can also be costly for inexperienced venture capitalists if the effort decision is not observable. Syndication entails leaving part of the firm's equity to the syndicate partner, which weakens the venture capitalist's incentives to exert effort. We find that since syndication is more likely for inexperienced venture capitalists, they are more likely to bear this additional cost of syndication.

The original contributions of the paper are first to propose a model where syndication arises endogenously. Syndication is not the unique way to achieve coordination, though. For instance, contractual arrangements involving transfers between venture capitalists are equally valid in our setting. We view these transfers as less likely, since venture capital investments are typically 
governed by restrictive fund covenants. ${ }^{3}$ It is plausible that setting transfers from one fund to another generates additional costs to circumvent the funds investment restrictions. We suggest that syndication, because it avoids direct transfers between venture capitalists, can mitigate these problems and allow information gathering. Second, we highlight the importance of experience on the formation and efficiency of syndicates, and on the ex-post involvement of venture capitalists. To our knowledge, no other theoretical paper considers this dimension. ${ }^{4}$ This enables us to propose a number of empirical predictions and possible tests.

First, the model predicts that the level of experience should be a major determinant of the syndication decision. In particular, standalone investments should be performed by highly experienced venture capitalists. Two effects combine to sustain this result: first, as was already recognized in the literature, more experienced venture capitalists generate better signals (see Lerner (1994)). Second, syndication is more costly the higher the level of experience of venture capitalists: because they have more accurate appraisals, experienced venture capitalists have more to lose when disclosing a deal. This prediction is supported by the observations of Hopp and Rieder (2006) that more experienced German venture capitalists syndicate much less than inexperienced ones. Also, a natural consequence of this result is that more syndication should arise in countries where the venture capital industry is young and rather inexperienced. ${ }^{5} \mathrm{~A}$ second prediction of the model is that the uncertainty of the portfolio firm, or of the industry in which venture capitalists invest, should also call for more syndication. This is consistent with the analyses of Bygrave (1987), and Chiplin and Wright (1997), who document that syndication is positively related to the level of uncertainty, and of Brander et al. (2002) who measure that standalone investments have less variability than syndicated ones. Another implication of this result is that more drastic innovations should induce more syndication: Hopp and Rieder (2006) do find that syndication is less frequent for more mature industries. Whether this result holds at the firm level is still an empirical issue. To test more precisely the predictions of our model, one could identify the product-market strategies of the portfolio firms, and define different degrees of innovativeness, in the spirit of Hellmann and Puri (2000). Third, our model relates the syndication decision to the involvement of venture capitalists. The predictions are two-fold: first, because inexperienced venture capitalists syndicate more, and because the expected returns are not very high, they do not exert enough effort. Second, experienced venture capitalists who invest alone provide more, but sometimes too much, effort. This last point is supported by Sapienza, Manigart and Vermeir (1996) who find a positive relationship between experience and involvement. It is also in line with Kaplan and Strömberg (2004) who find a positive

\footnotetext{
${ }^{3}$ See Gompers and Lerner (1996) for an analysis of such covenants.

${ }^{4}$ A recent paper by Cestone, Lerner and White (2006) considers the impact of experience in the formation of venture capital syndicates, but does not relate this to the ex-post involvement of venture capitalists.

${ }^{5}$ This prediction may seem at odd with the observation that syndication is very frequent in the US. Note however that the level of innovation of projects also impacts the level of syndication. The fact that venture capital in the US is notoriously directed towards innovative ventures could explain the high level of syndication.
} 
relationship between value-added activities and the equity stake of venture capitalists, and a negative relationship between the size of syndicates and value-added activities. Last, our results also address the issue of the relative profitability of standalone and syndicated investments. The empirical evidence is mixed: Brander et al. (2002) find that syndicated investments exhibit higher returns and higher volatility that stand-alone investments. Using different performance measures, Hege, Palomino and Schwienbacher (2006) find no significant relationship between the size of the syndicate and the level of excess returns. In our model, the relation between syndication and returns depends on the level of experience of venture capitalists: the important point is that, in contrast to alternative learning models, syndicated investments can exhibit higher expected returns than standalone investments. A possible test would be to include the level of experience of syndicate members, when testing the relation between returns and syndication.

In our model, syndication does not result from financial constraints or diversification motives but from the need to gather information while preventing competition. It is important to discuss to what extent our predictions are different, and are able to explain different empirical observations, from these competing rationales for syndication. An implication of the resource constraint motive is that syndication increases with the size of deals, and decreases with the size of venture capital funds. An implication of our model is that syndication increases with the level of uncertainty, but is not affected by deal size, or venture capital fund size. This could lead to opposite predictions if one considers that early-stage investments are typically more uncertain, but require less financial investments than late-stage rounds. Our model predicts more syndication for early-stage rounds, while the resource constraint motive suggests more syndication at later stages. There is not but limited evidence on this. If any, anecdotal evidence on UK investments suggests that the size of syndicates is smaller at later stages, while amounts invested are larger (Wright and Lockett (2003)). Another reason usually put forward to explain syndication is risk diversification. It is not easy to derive predictions from the risk mitigation motive though. From a theoretical point of view, it is not clear why VCs should care about diversification at the fund level, and why syndication should be the tool to mitigate risk. ${ }^{6}$ Some empirical evidence by Hopp and Rieder (2006) find that the concentration of VC portfolios increases with syndication. If any, this suggests that syndication is not used to hold a diversified portfolio of firms in different lines of business. While we believe that the risk mitigation and resource constraints definitely bear some relevance, it seems unlikely that they are the only determinant of the decision to syndicate.

Our paper is closely related to a few papers that explicitly focus on the syndication decision of financial intermediaries. Admati and Pfleiderer (1994) is probably the first paper where syndication emerges as the optimal arrangement. However they focus on sequential syndication,

\footnotetext{
${ }^{6}$ The limited partners who invest in venture capital funds are institutional investors who only invest a small portion of their endowments in the venture capital sector, and who can invest in several VC funds. In addition, if the VC firms themselves want to mitigate risk, they can achieve this through the management of several funds.
} 
whereby an initial venture capitalist remains in the firm to solve a lemon problem with future investors, while we focus on the formation of simultaneous syndicates. Pichler and Wilhelm (2001) provide a theory of syndicates in the investment banking industry. Their approach differs in the sense that they view syndication as a way to solve a moral hazard in team problem (see also Bubna (2002)), while we view syndication as a way to prevent competition. More recently, Bachman and Schindele (2006) and Cestone, Lerner and White (2006) both analyze models to explain the formation of syndicates: in Bachman and Schindele (2006), syndication can be a way to deter theft of idea by increasing the reputation loss of each syndicate member. Cestone, Lerner and White (2006) also analyze the syndication decision of a venture capitalist, and study how an optimally designed contractual arrangement of syndicates, can induce information revelation of the syndicate members. In their model, the cost of syndication raises from the adverse selection costs to induce truthfull information revelation, while in our model it raises from the disclosure of a profitable deal to a potential competitor. Their results share our view that the cost of syndication increases with the level of experience of venture capitalists, but they differ in the sense that, in their model, the initial venture capitalist does not always gain by choosing the most experienced partner. Another difference is that we explicitly consider the link between the screening process and the value-added efforts of venture capitalists, while the value-added dimension is absent in Cestone, Lerner, and White (2006).

This paper belongs naturally to the broader literature on venture capital. An important difference is that while most of the research activity has focused on the post-investment role of venture capitalists, ${ }^{7}$ and studied the financial contracts between venture capitalists and investors, ${ }^{8}$ we emphasize the pre-investment selection process of venture capitalists and focus on their syndication decision. This pre-investment selection process has not been much analyzed in the venture capital context. Kaplan and Strömberg (2004) study empirically the contents of venture capitalists' investment analysis, and their relation to the type of contracts and ex-post involvement of venture capitalists. Garmaise (2006) considers a model where venture capitalists have superior expertise in project evaluation compared to other agents. He however concentrates on the financial contract between the entrepreneur and the venture capitalist, while we focus on the contractual arrangement between venture capitalists, and study the formation of syndicates. Brander et al. (2002) also investigate the selection and value-added activities of venture capitalists, but they do not endogenize the syndication decision. Last, our paper is also related to Biais and Perotti (2003) who study the formation of a partnership by experts with different pieces of information. They share our assumption that revealing the existence of an investment project to

\footnotetext{
${ }^{7}$ See Admati and Pfleiderer (1994), Bergemann and Hege (1998), Cornelli and Yosha (2003), and Dessì (2005) for a theoretical analysis of sequential investment and the optimal continuation decision, Schmidt (2003), Renucci (2001), Repullo and Suarez (1999), or Casamatta (2003) on the advising role of venture capitalists, and Chan, Siegel and Thakor (1990), Hellmann (1998) or Cestone (2002) on the control exerted by venture capitalists.

${ }^{8}$ See Kaplan and Strömberg (2003) for a detailed empirical analysis of venture capital contracts.
} 
another expert can be costly. In a context of private information, they highlight the importance of the complementarity between the evaluations of the different experts to mitigate the risk of idea-stealing. In our model, evaluations are not complementary in the sense that the project can be valuable without their joint realization and syndication deters potential competition.

Last, our emphasis on the importance of information aggregation for financial decisions relates to the research field on the role of experts and certification in economics and finance. In some of that literature, experts are viewed as intermediaries who transmit information from informed to uninformed parties, and researchers have focused on the various incentives of each party (see Lizzeri (1999) on the incentives of intermediaries to manipulate information, FaureGrimaud, Peyrache and Quesada (2006) on the incentives of (informed) firms to effectively use that information, or Morrison and White (2006) on the externalities created by screening, in a model of bank regulation). Another branch of the literature emphasizes the incentive problems between a principal and experts (see Gromb and Martimort (2004) on the use of multiple experts to save on agency costs, Gerardi, MacLean, and Postlewaite (2005) on the optimal arrangement to aggregate information, and Baron and Besanko (1999) on the formation of informational alliance among experts). While all of that literature emphasizes information revelation problems, and focuses on the transmission of information to uninformed principals, we consider venture capitalists as principals, and do not study issues of information revelation.

The organization of the paper is the following. The next section presents the model and assumptions. Section 3 derives the socially optimal aggregation of information and investment decisions. Section 4 introduces the cost of potential competition between venture capitalists and provides a rationale for syndication. Section 5 analyses the syndication decision and the screening process when the initial venture capitalist is under the threat of potential competition. Section 6 introduces another cost of syndication when effort is not observable. Section 7 derives empirical predictions and proposes new tests. The last section concludes. Proofs are provided in the appendix, except those directly derived from the text.

\section{The model}

We consider the situation faced by a risk-neutral, cash-poor entrepreneur who needs an initial outlay $I$ to start an innovative investment project. The project yields a verifiable risky outcome

$\widetilde{R}$. For simplicity, we assume that the project can either succeed or fail, hence $\widetilde{R}$ can take two values: $R>0$ in case of success and 0 in case of failure. The probability of success depends on the quality of the project. If the project is good, the probability of success is $p_{h}$ (thus $1-p_{h}$ is the probability of failure of a good project), while if the project is bad, the probability of success 
is $p_{l}<p_{h} .{ }^{9}$ We assume that only good projects are profitable. With risk-neutral agents, and a riskless interest rate normalized to zero, this implies that:

$$
p_{h} R>I>p_{l} R
$$

Since we are concerned with a new, innovative project, the true quality of the project is initially unknown. Denote $q_{0}$ the a priori probability that the quality of the project is good. This prior is common knowledge.

The entrepreneur must raise funds from outside investors. Some of those investors have specific expertise in financing innovative projects. We call them venture capitalists (hereafter VC) and assume they have the following characteristics. First, VCs have the ability to better identify the true quality of the projects they are proposed, while traditional, non-specialized investors cannot. ${ }^{10}$ This assumption reflects the fact that VCs concentrate their investments in specific lines of business and can use their expertise to infer the quality of new projects. Consequently, we assume that venture capitalists can complete an investment analysis, to obtain a signal related to the project true quality. For simplicity, we assume that generating this signal is costless. ${ }^{11}$ This signal can be either good $(s=H)$ or bad $(s=L)$ and is all the more precise that the venture capitalist's expertise is high. In other words, all venture capitalists have the ability to screen projects, but they have different levels of observable ability. This assumption captures the idea that although specialized in the same line of business, some venture capitalists may be more experienced than others. Formally, the signal $s_{i}$ received by a venture capitalist with expertise $\alpha_{i}$ has the following properties:

$$
\begin{aligned}
\operatorname{prob}\left(s_{i}=H / p_{h}\right) & =\alpha_{i}, \\
\operatorname{prob}\left(s_{i}=L / p_{l}\right) & =\alpha_{i},
\end{aligned}
$$

where $\alpha_{i} \in\left[\frac{1}{2} ; 1\right]$. The probability of receiving a good signal conditional on a project being good increases with the venture capitalist's expertise. After observing a signal, the venture capitalist updates his belief on the project's quality using Bayes' rule.

Second, VCs can also use their expertise to provide business advice once the project has been funded. ${ }^{12}$ Correspondingly, we assume that VCs can exert a costly contractible effort ${ }^{13}$ that

\footnotetext{
${ }^{9}$ In the remaining of the paper, we will indifferently refer to a good project, or to a project with success probability $p_{h}$ to denote a project of good quality.

${ }^{10}$ See Sahlman $(1988,1990)$ for instance.

${ }^{11}$ In standard models of sequential competition, such fixed costs could in principle constitute barriers to entry, and play a strategic role (see Bain (1956)). This is not the case in our model, since the second VC's entry depends exclusively on the first VC's willingness to let him entry. Therefore, introducing a fixed cost to generate the signal does not qualitatively modify the results, but heavily burdens the presentation of the model.

${ }^{12}$ See Gompers and Lerner (1999) or Hellmann and Puri (2002).

${ }^{13}$ In a first step, we leave aside incentive issues, and focus on the interaction between the perceived project quality, the investment, and the effort decision. The assumption of contractible effort is relaxed in section 6.
} 
increases the probability of success of the project, if the true quality is good. To keep things simple, there are only two possible levels of effort. If the $\mathrm{VC}$ exerts effort (decision $e$ ), he incurs a private cost $c>0$ and increases the probability of success of a good project by $\epsilon>0$ (the probability of success of a bad project remains unchanged). If the $\mathrm{VC}$ does not exert effort (decision $\not e$ ), the probability of success remains unchanged. The assumption that effort affects only good projects is motivated by the fact that the returns to "living dead" projects are typically very low (close to zero), whatever the effort of the VCs. Bad projects in our model refer to those types of projects. ${ }^{14}$ Another important assumption is that only one agent needs to exert effort. ${ }^{15}$ This is in line with casual observation about the role of the lead venture capital investor in a VC syndicate. As pointed by Wright and Lockett (2003) page 2085, "the degree of contact between the members of the syndicate and the investee is anticipated to differ according to their role. Absent this asymmetry of contact, there would be a considerable degree of duplication of effort between the lead and non-lead firms". Using survey data on the UK VC industry, Wright and Lockett (2003) find that lead VCs are more hands-on in monitoring, more likely to have frequent contacts with investees, and that they have more access to management-based information. We follow the features of the industry by assuming that only one effort is needed. ${ }^{16}$

The net present value of the project depends on the agents' beliefs, the project's quality, and the effort decision. Denote $q_{s_{i}}$ the updated belief after a signal $s_{i}$ is generated and $q_{s_{i}, s_{j}}$ the updated belief after two signals $s_{i}$ and $s_{j}$. For instance, after one signal, the NPV is written:

$$
N P V\left(e, q_{s_{i}}\right)=-I-c+q_{s_{i}}\left(p_{h}+\epsilon\right) R+\left(1-q_{s_{i}}\right) p_{l} R
$$

if the effort is exerted, and:

$$
N P V\left(\not k, q_{s_{i}}\right)=-I+q_{s_{i}}\left(p_{h}\right) R+\left(1-q_{s_{i}}\right) p_{l} R,
$$

if the $\mathrm{VC}$ does not exert effort. Consistent with the fact that very innovative projects, while potentially highly profitable, also have a highly uncertain quality, the a priori NPV of the project is negative, whatever the effort decision. Therefore, the entrepreneur needs to rely on VC financing to implement his project.

\footnotetext{
${ }^{14} \mathrm{An}$ important question is to what extent our results depend on this specification. The current specification allows us to obtain investment regimes in which it is optimal to invest and not to exert effort. Such regimes also occur if we take a multiplicative and symmetric effort term, where the probability of success $p$ is multiplied by $(1+\epsilon)$ for all types of projects. But they will disappear for instance with an additive and symmetric value-adding term. In that case, effort is always exerted when investment takes place, as long as $\epsilon R-c>0$. This specification generates a perfect correlation between the investment and the effort decision, and prevents us from studying the intensity of the effort exerted, according to the perceived quality of the project.

${ }^{15}$ We thus abstract from moral hazard in team problems.

${ }^{16}$ Note however that this needs not be the case for other types of syndicates. See for instance Pichler and Wilhelm (2001) for an analysis of moral hazard in team in the investment banking industry.
} 
The timing of the game is the following. The entrepreneur proposes an investment opportunity to a first $\mathrm{VC}$ (labelled $\mathrm{VC}_{1}$ ), who generates a signal $\mathrm{s}_{1}$. Then, $\mathrm{VC}_{1}$ can:

- either reject the project,

- or stop collecting information and invest immediately,

- or call for a second evaluation performed by a second $\mathrm{VC}$, labelled $\mathrm{VC}_{2}$.

In the latter case, we assume that the signals are freely observed by the two VCs. ${ }^{17}$ Last, if (and after) the project is implemented, $\mathrm{VC}_{1}$ takes the effort decision. ${ }^{18}$

\section{Optimal information aggregation and investment decision}

In this section, we determine $\mathrm{VC}_{1}$ 's optimal information gathering and investment policy. We assume that $\mathrm{VC}_{1}$ is able to capture all the project surplus, so that he maximizes the project's NPV. ${ }^{19} \mathrm{VC}_{1}$ asks for a second evaluation each time it increases the project's expected NPV, compared to the current NPV. This implies that at least one realization of the second signal must modify the initial investment decision. If not, the expected value of the project given $s_{2}$ is equal to the value of the project given $s_{1}$. Formally, $s_{2}$ is generated if and only if:

$$
\max \left\{0 ; N P V\left(e, q_{s_{1}}\right) ; N P V\left(\not e, q_{s_{1}}\right)\right\} \leq \mathrm{E}_{s_{2}} \max \left\{0 ; N P V\left(e, q_{s_{1}, s_{2}}\right) ; N P V\left(\not k, q_{s_{1}, s_{2}}\right)\right\}
$$

To keep the analysis as rich as possible, we want to ensure that it is sometimes optimal to invest, but not to exert effort. It must be the case that for some $\alpha_{1}, N P V\left(\not e, q_{s_{1}}\right)>N P V\left(e, q_{s_{1}}\right)>$ 0 . Otherwise, the decision to invest would immediately trigger effort. Intuitively, this is the case if the effort is not very efficient, which is formally stated in the next assumption.

Assumption 1 Effort is not very efficient:

$$
c\left(p_{h}-p_{l}\right) \geq \epsilon\left(I-p_{l} R\right)
$$

\footnotetext{
${ }^{17}$ See Biais and Perotti (2003) or Cestone, White and Lerner (2006) on the issue of privately observed signals.

${ }^{18}$ Alternatively, the effort could be decided by $\mathrm{VC}_{2}$ : the identity of the lead $\mathrm{VC}$ investor does not modify the results.

${ }^{19}$ The model can easily be extended to the case where the entrepreneur has a fixed fraction of surplus. Also, this assumption can be an equilibrium outcome in specific bilateral negotiation games -see Casamatta and Haritchabalet (2006).
} 
Figure 1 represents the optimal information aggregation and investment decision of $\mathrm{VC}_{1}$, according to his, as well as the other VC's, level of experience. The $x$ axis measures the level of experience of $\mathrm{VC}_{1}$, while the $y$ axis measures the level of experience of $\mathrm{VC}_{2} \cdot{ }^{20}$ This figure describes the choice made by $\mathrm{VC}_{1}$ for any couple $\left\{\alpha_{1} ; \alpha_{2}\right\} .{ }^{21}$ The figure restricts to the case where $\mathrm{VC}_{1}$ has received a good signal. In the dotted lines regions, $\mathrm{VC}_{1}$ does not collect the second signal, and makes his investment decision alone. In the plain regions, he collects the second signal : investment and effort decisions are specified according to the realization of the second signal.

When $\alpha_{1}$ is below a threshold $\alpha_{I}$, in the lower left side of the picture, $\mathrm{VC}_{1}$ prefers not to invest alone even after a good signal. He then needs a second evaluation to confirm his own appraisal. Note that the more confident $\mathrm{VC}_{1}$ is about his own evaluation, the less precise the second evaluation has to be to confirm his signal. Consequently, one observes that the minimum level of $\mathrm{VC}_{2}$ 's experience to collect $s_{2}$ decreases with $\mathrm{VC}_{1}$ 's experience: it is represented by the decreasing curve $\varphi_{I, q}\left(\alpha_{1}\right)$.

When $\mathrm{VC}_{1}$ is more experienced (above $\alpha_{I}$ ), in the lower right side of the picture, he invests if he obtains a good signal. A second piece of information can be useful to deter investment. In that case, the more experienced $\mathrm{VC}_{1}$ is, the higher must be the experience of $\mathrm{VC}_{2}$ to make him change his mind: this effect is represented by the increasing curve $\varphi_{\mathbb{I}, d}\left(\alpha_{1}\right)$.

The second piece of information can also be used to modify the effort decision. For instance, if $\mathrm{VC}_{1}$ is moderately experienced and obtains a good signal (i.e. if $\alpha_{1} \in\left[\alpha_{I}, \alpha_{e}\right]$ ), he prefers to invest and not to exert effort unless he receives a second good signal. The experience of $\mathrm{VC}_{2}$ required to exert effort decreases then with $\mathrm{VC}_{1}$ 's own experience (see the curve $\varphi_{e}\left(\alpha_{1}\right)$ ). The opposite arises when $\mathrm{VC}_{1}$ is very experienced and is discouraged to exert effort after bad news from $\mathrm{VC}_{2}$ (see the curve $\varphi_{\phi}\left(\alpha_{1}\right)$ ).

The above discussion is summarized in the next proposition.

Proposition 1 The minimum level of experience of $V C_{2}$ increases (decreases) with $V C_{1}$ 's own experience when they disagree (agree) on the investment or effort decision.

\footnotetext{
${ }^{20} \mathrm{~A}$ detailed explanation for the determination of the different functions and variables is provided in the appendix.

${ }^{21}$ We have not considered the optimal choice of $\mathrm{VC}_{2}$ 's experience. This is because in our setting, the optimal value of $\alpha_{2}$ is trivially 1 . We implicitly assume that choosing exactly the level of experience of $\mathrm{VC}_{2}$ might be impossible or difficult. The venture capital industry may be more or less well developed, which restrains the set of available levels of VC experience. Even when experienced VCs exist in the economy, time constraints may prevent a given $\mathrm{VC}$ to actually process an investment candidate, which reduces again the set of available syndicate partners. A way to model this would be to introduce a matching technology that randomly draws the level of experience $\alpha_{2}$ available to $\mathrm{VC}_{1}$ when he wants to syndicate.
} 


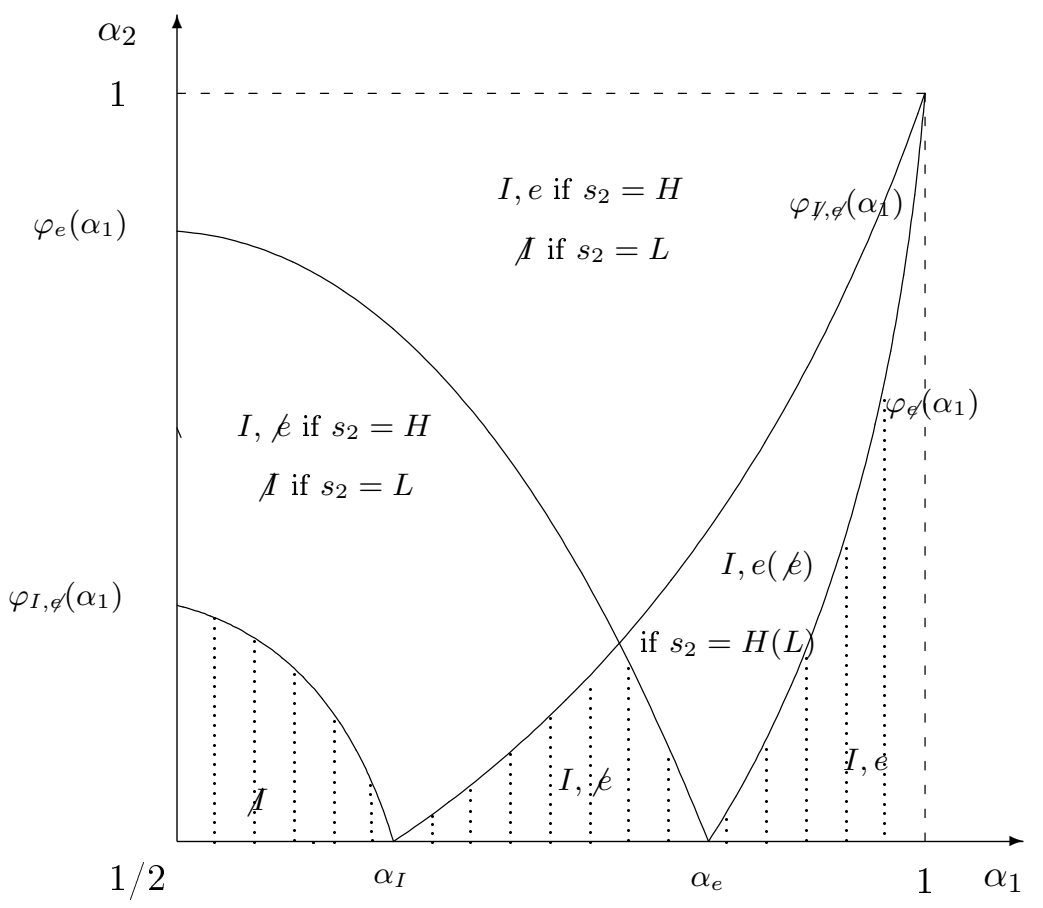

Figure 1: Optimal Information gathering when $s_{1}=H$.

Note that these results rely on the dynamics of $q$ induced by bayesian updating. In particular, they do not rely on our specific binary investment model. To assess this, we present in appendix page 28 a continuous investment version of our generic model and state that the results of proposition 1 are qualitatively unchanged.

\section{Potential competition between venture capitalists}

The previous paragraph determined the information aggregation and investment decision when $\mathrm{VC}_{1}$ is able to capture the project's NPV. We now introduce the possibility that $\mathrm{VC}_{2}$ proposes a competing offer to the entrepreneur, if he is contacted by $\mathrm{VC}_{1}$. Asking for a second piece of information becomes costly for $\mathrm{VC}_{1}$ : disclosing the investment opportunity to the second $\mathrm{VC}$ destroys his monopoly position. ${ }^{22}$ To determine the optimal information aggregation strategy of

\footnotetext{
${ }^{22}$ This is however different from standard sequential competition models, because $\mathrm{VC}_{1}$ decides whether or not to allow $\mathrm{VC}_{2}$ to enter the market: there is no threat of entry from $\mathrm{VC}_{2}$, and there is no room for entry-deterrence
} 
$\mathrm{VC}_{1}$, we first need to determine what pay-offs can be obtained by each party if $\mathrm{VC}_{2}$ is contacted.

\subsection{The outcome of potential competition}

The timing of the game is modified as follows: if $\mathrm{VC}_{1}$ discloses the project to a second $\mathrm{VC}$, we assume that both VCs observe freely the two signals $s_{1}$ and $s_{2}$ generated by their analyses. After information is observed, they can either make competing (separate) offers, or negotiate and make a joint offer. This timing implicitly assumes that competing offers cannot be ruled out, i.e. that $\mathrm{VC}_{1}$ cannot write a non competing agreement with $\mathrm{VC}_{2}$. This assumption can be justified by the fact that i) since $\mathrm{VC}_{1}$ has not invested into the project yet, he cannot claim to have property rights over the project, that could rule out competing offers; ii) forcing the second VC to sign a non-competing clause goes against all competition enhancing policies. We will come back to this point when discussing the possible contractual arrangements between VCs.

To solve the model, we now describe the outcome of the game if VCs do make competing offers. Offers are simultaneous. If the project's NPV (conditional on the signals) is negative, neither $\mathrm{VC}_{1}$ nor $\mathrm{VC}_{2}$ will propose to finance the entrepreneur's project. If the project's NPV is positive, each VC separately proposes a financial agreement to the entrepreneur, specifying the share of financial income (denoted $\delta_{i}, i \in\{1,2\}$ ) that they require in exchange for the initial investment $I$. Since the two VCs have the same evaluation, the game thus boils down to standard Bertrand competition. At equilibrium, we thus have $\delta_{1}=\delta_{2}$, and each VC earns zero profit in expectation.

Alternatively, the two VCs can negotiate for a joint offer ${ }^{23}$ to share the project's NPV. We make the assumption that such a joint offer does not modify the entrepreneur's bargaining power. ${ }^{24}$ As is standard in this type of setting, the bargaining between the two VCs leads to the Nash solution: when the VCs have the same bargaining power, they split evenly the surplus from negotiation. ${ }^{25}$ If negotiation fails, as stated above, the two VCs engage in Bertrand competition and obtain zero profits. Their reservation utility in the bargaining process is thus equal to zero,

strategies by $\mathrm{VC}_{1}$, as in Spence (1977) or Dixit (1979). This is also why introducing costly signals will not involve strategic, barrier-to-entry effects in the model.

${ }^{23}$ This assumption departs from Garmaise (2006) who focuses on competition between VCs, in an asymmetric information setting.

${ }^{24}$ If the entrepreneur's bargaining power increases with the number of investors, that will creates an additional cost of syndication, and reinforce our result that syndication is costly, especially for the most experienced VCs. For simplicity, we choose not to include this cost in the analysis. Note also that our assumption is consistent with the way we view syndication: the entrepreneur bargains with a syndicate, and not with two (separate) investors. From the entrepreneur's point of view, there is thus no difference between bargaining with a single investor and with a syndicate.

${ }^{25}$ Relaxing the assumption of equal bargaining power, by allowing for instance the bargaining power of each party to increase with his relative level of experience, does not modify qualitatively the results. 
and the surplus from negotiation is equal to the project's NPV. Each VC thus obtains half of the project's NPV from negotiating.

The cost of gathering information incurred by $\mathrm{VC}_{1}$ appears now clearly. If he sticks to his own evaluation, he enjoys a monopoly position, and captures the whole project's NPV. If however he calls for a second evaluation, because of the threat of competition, he cannot capture more than half of the project's NPV. Intuitively, there will be cases where the second signal is valuable (i.e. it increases the NPV), but $\mathrm{VC}_{1}$ loses too much to be willing to gather information. $\mathrm{VC}_{1}$ 's incentives to gather information will be analyzed more formally in section 5 .

\subsection{The contractual arrangement between VCs}

We now investigate which contracts can implement the Nash bargaining solution. The contractual elements can be contingent on the following verifiable variables: the amount invested, the investment decision and the final income generated by the project. We thus exclude signals from being part of the contract. Indeed, although signals are observable by the two $\mathrm{VCs}$, it is very unlikely that they can be verifiable by an outside court. Last, contracts are signed after signals are observed.

A contract determines i) $\mathrm{VC}_{i}$ 's contribution to the total initial outlay $I$, denoted $C_{i}(I)$, with $\sum_{i} C_{i}(I)=I$ ii) $\mathrm{VC}_{i}$ 's return according to the final income $R_{i}(\tilde{R})^{26}$ and iii) transfers between VCs at the investment date, denoted $T_{i}$, such that $\sum_{i} T_{i}=0$. Any contract $\left\{C_{i}(I) ; R_{i}(\tilde{R}) ; T_{i}\right\}$ verifying $\forall i$ :

$$
T_{i}-C_{i}(I)+\mathrm{E}_{\tilde{\mathrm{R}}} \mathrm{R}_{\mathrm{i}}(\tilde{\mathrm{R}})=\frac{1}{2} \mathrm{NPV}\left(\mathrm{s}_{1}, \mathrm{~s}_{2}\right),
$$

implements the Nash-bargaining solution. Examples of possible contracts are:

$$
\text { Ex. } 1:\left\{\begin{array}{ll}
T_{1}=-\frac{1}{2} N P V & T_{2}=\frac{1}{2} N P V \\
C_{1}(I)=I & C_{2}(I)=0 \\
R_{1}(R)=R & R_{2}(R)=0 .
\end{array} \quad \text { Ex. } 2:\left\{\begin{array}{l}
T_{1}=0 \quad T_{2}=0 \\
-C_{1}(I)+\mathrm{E}_{\tilde{\mathrm{R}}} \mathrm{R}_{1}(\tilde{\mathrm{R}})=\frac{1}{2} \mathrm{NPV} \\
-C_{2}(I)+\mathrm{E}_{\tilde{\mathrm{R}}} \mathrm{R}_{2}(\tilde{\mathrm{R}})=\frac{1}{2} \mathrm{NPV} \\
C_{1}(I)+C_{2}(I)=I \\
R_{1}(R)+R_{2}(R)=R, \text { with } R_{i} \geq 0
\end{array}\right.\right.
$$

Example 1 is a contract whereby $\mathrm{VC}_{1}$ buys to $\mathrm{VC}_{2}$ the right to be the sole investor in the project: the initial transfer compensates $\mathrm{VC}_{2}$ accordingly. Example 2 is a contract involving no initial transfer. Note that all contracts in the form of Example 2 involve co-ownership of the firm by the two VCs. Indeed, even if one VC's contribution is nul $\left(C_{i}=0\right)$, he receives a strictly positive share of equity $\left(R_{i}(R)>0\right)$. In the remainder of the analysis, such contracts involving no initial transfers will be denoted syndicated investments.

\footnotetext{
${ }^{26}$ Recall that $\tilde{R}$ can take two values: $R$ or 0 . Quite plausibly, we assume limited liability: $\sum_{i} R_{i}(\tilde{R}) \leq \tilde{R}$ and $R_{i}(\tilde{R}) \geq 0$. This implies that $R_{1}(0)=R_{2}(0)=0$.
} 
In principle, all types of contracts are equally valid. We view contracts with transfers as less likely, since venture capital investments are typically governed by restrictive fund covenants. ${ }^{27} \mathrm{It}$ is plausible that setting transfers from one fund to another generates additional costs to circumvent the funds investment restrictions. For these reasons, we argue that syndicated investments, where the two VCs are co-owners of the firm, are the most frequent contractual arrangements to implement the Nash-bargaining solution.

The contracts derived above are decided upon after observing signals, which seems more in line with practice. It is important though to discuss what would happen if contracts could be signed before disclosing the project to the second $\mathrm{VC}$, in the spirit of the ex-ante contracts considered in Anton and Yao (1994). ${ }^{28}$ Clearly, the investment contract proposed by $\mathrm{VC}_{1}$ to $\mathrm{VC}_{2}$ before disclosing the project is plagued by asymmetric information, because $\mathrm{VC}_{2}$ does not know $\mathrm{VC}_{1}$ 's signal yet. Separating contracts would typically entail that $\mathrm{VC}_{1}$ keeps a higher fraction of returns, and invests a higher fraction of investment to credibly signal his good evaluation. ${ }^{29}$ But, our model is different in that $\mathrm{VC}_{1}$ does not need to sell his project to $\mathrm{VC}_{2}$, but only needs a second piece of information. Avoiding to trade with $\mathrm{VC}_{2}$ allows him to save on adverse selection costs. The (rather trivial) optimal contract is simply for $\mathrm{VC}_{1}$ to propose to invest alone and to get all the proceeds from the investment, whatever his signal. This is exactly the non competing contract that we ruled out previously. One reason for ruling it out (on top of such contracts being illegal in practice) is that it might not be robust to collusion with a third VC. Even if $\mathrm{VC}_{2}$ commits not to invest in the project after observing the two signals, it should be hard to prevent him from making a competing offer through another fund. Another reason for not considering such contracts would be to consider that the second signal is not publicly observed. In that case, $\mathrm{VC}_{1}$ would need to offer an incentive compatible contract to make $\mathrm{VC}_{2}$ reveal his information: this would give rise to informational rents, and the ex-ante contract described above would not be optimal. ${ }^{30}$ The cost of information revelation is studied in other models of information gathering (Biais and Perotti (2003), Cestone, Lerner and White (2006)), and we focus here on the cost of potential competition.

\footnotetext{
${ }^{27}$ See Gompers and Lerner (1996) for an analysis of such covenants.

${ }^{28}$ In theory, one could also conceive to sign contracts even before the first VC receives his signal, specifying what would be the investment contract if $\mathrm{VC}_{1}$ contacts $\mathrm{VC}_{2}$ : considering contracts signed after the first signal amounts for $\mathrm{VC}_{1}$ to select his preferred contract in the class of ex-ante contracts.

${ }^{29} \mathrm{~A}$ similar feature arises in Anton and Yao (1994) who show that such ex-ante contracts are possible if the seller $\left(\mathrm{VC}_{1}\right)$ does not have limited liability, and can signal the quality of his project by guaranteeing possible future losses of the buyer.

${ }^{30}$ We thank an anonymous referee for raising this point.
} 


\section{The decision to syndicate}

In this section, we investigate when syndication actually takes place and compare the syndication decision to the efficient information aggregation derived in section 3. The trade-off faced by $\mathrm{VC}_{1}$ is now the following. He can rely on his own evaluation and enjoy a monopoly position. Alternatively, he can call for a second evaluation that yields more precise information on the project's true quality. In that case, $\mathrm{VC}_{1}$ gives up half of the monopoly profits to avoid competition as stated in section 4 . Formally, $\mathrm{VC}_{1}$ chooses to syndicate if and only if:

$$
\max \left\{0 ; N P V\left(e, q_{s_{1}}\right) ; N P V\left(\phi, q_{s_{1}}\right)\right\} \leq \mathrm{E}_{s_{2}} \frac{1}{2} \max \left\{0 ; N P V\left(e, q_{s_{1}, s_{2}}\right) ; N P V\left(\phi, q_{s_{1}}, s_{2}\right)\right\} .
$$

We then compare this syndication decision to the optimal information gathering strategy (from section 3).

Proposition 2 If $V C_{1}$ is rather inexperienced (in the sense that $\alpha_{1} \leq \alpha_{I}$ ) or if $V C_{1}$ has received a bad signal, syndication occurs whenever information gathering is optimal. The threshold $\alpha_{I}$ is defined in the appendix page $2 \%$.

Proposition 2 means that potential competition has no incidence on inexperienced (or pessimistic) VCs. The intuition is the following: inexperienced VCs are not able to screen efficiently the projects under evaluation. Therefore they have nothing to lose when contacting a second evaluator (their monopoly profits are equal to zero). Since syndication is costless, it takes place each time the second piece of information is valuable, and the project is profitable. The same is true if $\mathrm{VC}_{1}$ receives a bad signal: it is not profitable to invest alone, and $\mathrm{VC}_{1}$ contacts $\mathrm{VC}_{2}$ anytime his information is valuable, as defined in section 3 . Both the realization of the signal and the experience of the venture capitalist determine the extent to which he is hurt by potential competition.

Proposition 3 Potential competition between VCs affects the screening process in the following way:

- an experienced $V C_{1}$, in the sense that $\alpha_{1} \in\left[\alpha_{I}, \alpha_{e}\right]$, demands a higher than optimal level of $V C_{2}$ 's experience to form a syndicate.

- A very experienced $V C_{1}$, in the sense that $\alpha_{1}>\alpha_{e}$, never forms a syndicate and forgoes gathering information.

The threshold $\alpha_{e}$ is defined in the appendix page 27. 
When $\mathrm{VC}_{1}$ is rather experienced, his evaluation is precise enough to find it profitable to invest alone. As a consequence, syndication is costly because $\mathrm{VC}_{1}$ has to give up positive monopoly profits. To compensate this loss, he requires a more precise signal $s_{2}$ (compared to the first best), hence a more experienced partner. Since the monopoly profits of $\mathrm{VC}_{1}$ increase with his level of experience, he is more and more reluctant to syndicate (or, he requires more and more experienced partners): this may reach the point at which no level of $\mathrm{VC}_{2}$ 's experience satisfies $\mathrm{VC}_{1}$ 's requirement. In those cases, the cost of potential competition is too large compared to the benefits of more precise information. This does not happen in the first best since, unless $\mathrm{VC}_{1}$ has perfect information, there always exists a degree of precision such that the second piece of information is valuable.

Corollary 1 Potential competition leads to overinvestment when $V C_{1}$ is sufficiently experienced (in the sense that $\alpha_{1}>\alpha_{I}$ ).

The intuition of corollary 1 is the following. When $\mathrm{VC}_{1}$ is sufficiently experienced so that he can invest alone after a good signal, the evaluation made by a second $\mathrm{VC}$ is valuable to discourage investment in case of a bad signal $s_{2}$. Because of potential competition, $\mathrm{VC}_{1}$ does not gather information each time it is optimal to do so, and invests too much.

Corollary 2 Potential competition leads to overprovision (resp. underprovision) of effort when $V C_{1}$ 's experience is greater (resp. smaller) than $\alpha_{e}$.

When $\mathrm{VC}_{1}$ is the sole investor, he exerts the optimal level of effort given his own information. When he is very experienced (i.e. when $\alpha_{i} \geq \alpha_{e}$, he always exerts effort if his signal is good, while a bad signal $s_{2}$ could be used to discourage effort (if $\alpha_{2}>\varphi_{q}\left(\alpha_{1}\right)$, as depicted on figure 1). At the opposite, when $\mathrm{VC}_{1}$ is moderately experienced (i.e. when $\alpha_{i} \in\left[\alpha_{I}, \alpha_{e}\right]$, he never exerts effort if his signal is good, while a good signal $s_{2}$ would encourage effort (if $\alpha_{2}>\varphi_{e}\left(\alpha_{1}\right)$ ). When potential competition deprives $\mathrm{VC}_{1}$ of the second evaluation, he exerts too much effort in those cases where the second signal would have discouraged effort, and where $\mathrm{VC}_{1}$ prefers not to contact $\mathrm{VC}_{2}$. Similarly, he exerts too little effort in those cases where the second signal would have encouraged effort, and where $\mathrm{VC}_{1}$ does not contact a second evaluator.

The results stated in propositions 2 and 3 and in corollaries 1 and 2 are illustrated in figure 2 (for the case where $s_{1}=H$ ). As before, the dotted line regions represent the zones where $\mathrm{VC}_{1}$ does not contact a second venture capitalist after receiving a good signal. The plain (white) regions represent the zones where $\mathrm{VC}_{1}$ contacts $\mathrm{VC}_{2}$, and forms a syndicate when investment takes place. Each region specifies the optimal investment and effort decisions according to the signals and the levels of experience. It is useful to compare figure 2 and figure 1 to understand how potential competition alters the aggregation of information, as well as the investment decisions. 


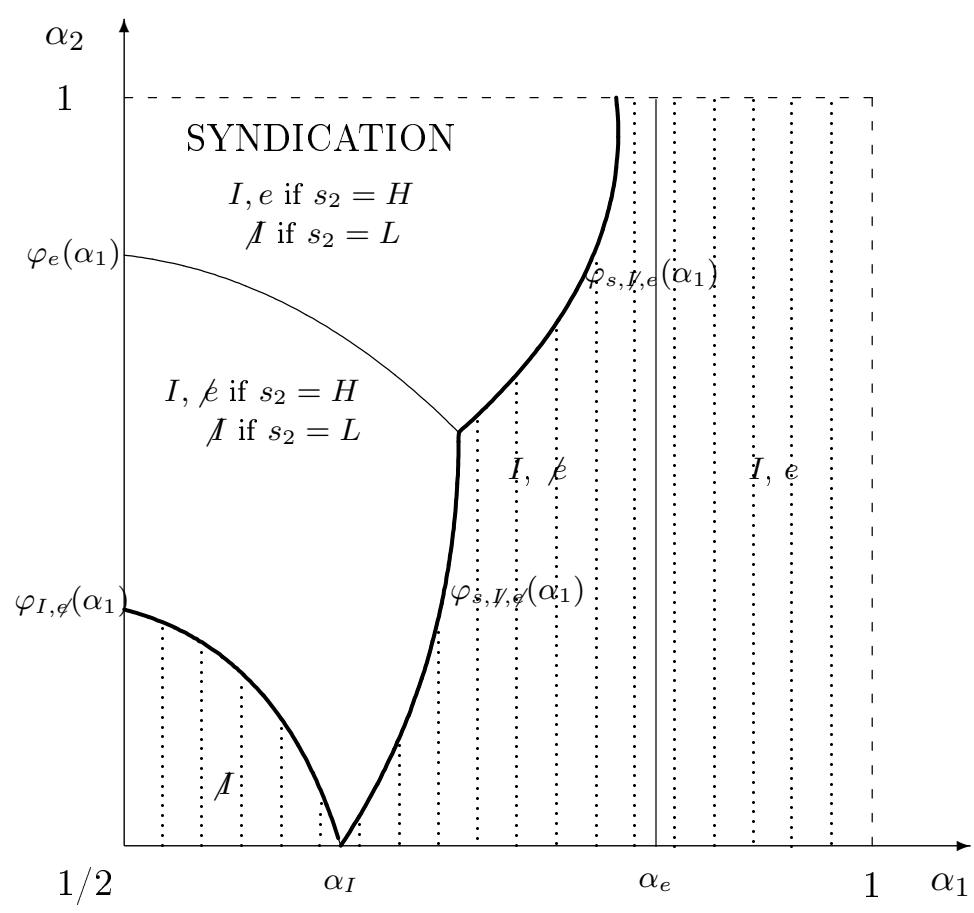

Figure 2: Syndication decision when $s_{1}=H$.

First, inexperienced VCs are not affected by the cost of potential competition: when $\alpha_{1}<\alpha_{I}$, both figures coincide, and the threshold above which $\mathrm{VC}_{1}$ calls for a second expertise remains the same $\left(\varphi_{I, \phi}\left(\alpha_{1}\right)\right)$. This illustrates the result of proposition 2: there is no cost to syndicate for inexperienced VCs since they have nothing to lose. Second, the information gathering region shrinks when the experience of $\mathrm{VC}_{1}$ grows. For instance, when $\alpha_{1} \in\left[\alpha_{I}, \alpha_{e}\right]$, figure 1 teaches us that $\mathrm{VC}_{1}$ should contact $\mathrm{VC}_{2}$ whenever $\alpha_{2} \geq \varphi_{\mathbb{H}, q}\left(\alpha_{1}\right)$ and refrain from investing if the second signal is bad. From figure 2 one can see that $\mathrm{VC}_{1}$ contacts $\mathrm{VC}_{2}$ to refrain from investing if $\alpha_{2} \geq \varphi_{s, I, \ell}\left(\alpha_{1}\right)>\varphi_{I, \ell}\left(\alpha_{1}\right)$. This is the cost of potential competition highlighted in proposition 3: competition prevents $\mathrm{VC}_{1}$ from collecting a second evaluation each time he should. Third, the cost of syndication increases with $\mathrm{VC}_{1}$ 's experience and can finally deter information gathering. This effect is easily seen in the case where $\mathrm{VC}_{1}$ is very experienced $\left(\alpha_{1}>\alpha_{e}\right)$. The information gathering zone (when $\alpha_{2}>\varphi_{\phi}\left(\alpha_{1}\right)$ ) has disappeared from figure 2. Last, observe that one region, that was defined by $\alpha_{2} \in\left[\max \left[\varphi_{e}\left(\alpha_{1}\right), \varphi_{\phi}\left(\alpha_{1}\right)\right], \varphi_{\mathbb{I}, q}\left(\alpha_{1}\right)\right]$ completely disappears: this is the region where the second signal is used to modify the effort, but not the investment decision. As a consequence, a moderately experienced $\mathrm{VC}_{1}$ exerts too little effort and a very experienced $\mathrm{VC}_{1}$ exerts too much effort as stated in corollary 2 . 


\section{Syndication and unobservable effort}

In the previous sections, we assumed that the effort decision was contractible to abstract from moral hazard issues. We now relax this assumption and assume that the effort exerted by $\mathrm{VC}_{1}$ is unobservable and cannot be contracted upon. In our simple setting, if $\mathrm{VC}_{1}$ remains the sole investor, moral hazard is irrelevant: $\mathrm{VC}_{1}$ is the only owner of the firm, he reaps the full benefit of effort, and is always induced to exert effort whenever it is optimal to do so (conditional on his information).

If $\mathrm{VC}_{1}$ decides to form a syndicate, his effort decision might be altered because he has to concede a fraction $1-\gamma$ of equity to $\mathrm{VC}_{2} \cdot{ }^{31} \mathrm{VC}_{1}$ still bears the full cost of his effort, but recoups only a fraction of the benefit, which can weaken his incentives to exert effort. Define $\gamma_{\max }(<1)$ the maximal share of equity that $\mathrm{VC}_{1}$ can keep with a syndication contract; $\gamma_{\max }$ corresponds to the case where $\beta=1$, and is defined by (in the case where effort is profitable):

$$
\gamma_{\max }=\frac{\left(\frac{1}{2} N P V(e, q)+I+c\right)}{q\left(p_{h}+\epsilon\right) R+(1-q) p_{l} R} .
$$

Also, the incentive compatibility condition ensuring that $\mathrm{VC}_{1}$ prefers to exert effort given his stake in the firm $\gamma$ is written:

$$
\gamma \geq \frac{c}{q \epsilon R}
$$

Therefore, $\mathrm{VC}_{1}$ syndicates and exerts effort if $\gamma \in\left[\frac{c}{q \in R}, \gamma_{\max }\right]$. As long as this interval exists, moral hazard has no bite because it is always possible to set $\gamma$ such that $\mathrm{VC}_{1}$ exerts the optimal effort level. In the case where the interval does not exist, it is not possible to induce $\mathrm{VC}_{1}$ to exert effort although it would be optimal to do so. In that case, syndication between VCs leads to underprovision of effort.

When is syndication likely to deter effort? As illustrated in figure 2, if $\mathrm{VC}_{1}$ syndicates, it is optimal to exert effort when $\alpha_{2}>\varphi_{e}\left(\alpha_{1}\right)$. This means that along the curve representing $\varphi_{e}\left(\alpha_{1}\right)$, $\frac{c}{q \in R}=1$, and $\mathrm{VC}_{1}$ exerts effort if and only if he owns $100 \%$ of the firm's equity. Clearly, for $\alpha_{2}$ slightly above $\varphi_{e}\left(\alpha_{1}\right), \mathrm{VC}_{1}$ forms a syndicate to invest, and has too small a stake in the firm to be induced to exert effort: the interval $\left[\frac{c}{q \epsilon R}, \gamma_{\max }\right]$ does not exist. It follows from the previous discussion that there exists a region above $\varphi_{e}\left(\alpha_{1}\right)$ where it is optimal to exert effort, but where it is not possible to induce $\mathrm{VC}_{1}$ to do so.

This gives the following proposition which is graphically illustrated with a numerical example in the appendix page 33 .

\footnotetext{
${ }^{31}$ Note that in our setting, equity is an optimal contract to induce one agent to exert effort. This is because the final income can only be $R$ or 0 : it is not possible to distinguish between debt, equity, or any other financial contract.
} 
Proposition 4 Moral hazard leads to underprovision of effort under syndication, i.e. when $V C_{1}$ is not very experienced.

The previous section points out one cost of potential competition, which is the insufficient aggregation of information and inefficient screening process. Because they have more to lose when forming a syndicate, experienced VCs essentially bear this cost. Inexperienced VCs are immune from the threat of potential competition and can aggregate through syndication all valuable information. This section highlights another cost of syndication that is borne primarily by inexperienced VCs. When effort is not observable, there is a tension between the need to give up a fraction of the firm's equity to form a syndicate and the need to keep enough shares to be induced to work. We show that this tension leads to underprovision of effort. Note that moral hazard affects the regions where syndication takes place. Intuitively, since there is less syndication for more experienced $\mathrm{VCs}$, this cost decreases with $\mathrm{VC}_{1}$ 's experience.

\section{Empirical predictions and possible tests}

This model allows to derive a number of empirical predictions concerning the formation of syndicates (who syndicates with whom, and for which projects), the post-investment involvement of the syndicate partners, as well as the profitability of syndicated investments. We present below the main predictions of our model, and try to assess their empirical relevance compared to alternative explanations of syndication. Finally, we suggest possible empirical tests to fit more accurately our predictions.

\section{The empirical predictions of our model}

- A central prediction of our model is that the level of experience of venture capitalists should be a major determinant of their decision to syndicate. In particular, standalone investments should be performed by highly experienced VCs. In our model this happens for two reasons. The first one is rather obvious: more experienced VCs are able to screen more efficiently projects, and circumvent more accurately the project risk. Therefore, there is less need for syndication. The second one is directly linked to the cost of disclosing deals to potential competitors: because they have more accurate evaluations, experienced VCs are more vulnerable to potential competition. In other words, experienced VCs have more to lose when disclosing a deal. Having a higher cost and a lower benefit of forming a syndicate, they syndicate less. While the first argument was already recognized in the literature (Lerner (1994)), the second is specific to our paper. We believe that the second argument is important, in particular for early stage investments, where uncertainty is so high that even experienced VCs could benefit from the assessment of a peer. According 
to our analysis, what refrains them from syndicating is the cost of losing monopoly rents. This prediction is supported by various empirical findings: studying a sample of biotech investments, Lerner (1994) finds that experienced VCs syndicate with similarly experienced VCs. In addition, Hopp and Rieder (2006) document from a sample of German venture capital investments that more experienced VCs syndicate much less than their inexperienced counterparts. For instance, VC firms which have undertaken more deals syndicate less, as well as those which have undertaken a larger proportion of their deals in Germany.

- Our results also imply that, other things equal, the uncertainty of the portfolio firms, or of the industry where VCs invest in, should have an influence on the level of syndication of venture capitalists. Indeed the venture capitalists' ability to generate precise signals on the projects' quality $\left(\alpha_{i}\right.$ in the model) also depends on the general level of uncertainty of those projects. Presumably, the venture capital industry ability to screen projects, should be lower the younger the firm, or the more innovative the firm's business. For those projects or industries, it is unlikely that $\mathrm{VCs}$ with very high $\alpha_{i}$ exist. As a consequence, one should observe more syndication for those industries. This is supported by evidence both at the firm, and at the industry level. Different papers have reported that syndication is positively related to the level of uncertainty of projects (Bygrave (1987), Chiplin and Wright (1997), Amit, Brander, and Antweiler (2002)), or to the age of the funded firms, early stage firms exhibiting more syndication (Hopp and Rieder (2006)). Some papers have also reported that the industry itself is an important determinant of syndication. Hopp and Rieder (2006) find that more mature industries, like industrial products and services, exhibit much lower levels of syndication that the biotech or internet sectors (see also Lehman and Boschker (2006)). To the extent that projects in mature industries are more easily readable (say, because comparisons are easier, valuations based on ratio comparisons more accurate), the precision of VCs signals is likely to be higher than in more innovative sectors.

- An original feature of our analysis is to study jointly two sources of value-added of venture capitalists, which are usually investigated separately in the literature, namely their ability to screen projects, and their ability to provide value-enhancing advice. Our predictions are twofold. First, because inexperienced VCs syndicate, they do not exert enough effort. This is because syndicate members have to share the returns from the project, which can discourage the lead VC's effort. Note however that syndication does not necessarily imply underprovision of effort: When expected returns are quite high, it is possible to conceive an incentive compatible return sharing scheme. As a consequence, underprovision of effort because of syndication is more likely when (some) syndicate members are inexperienced (i.e. when expected returns are not very high). Second, the model predicts that experienced VCs who invest alone should provide more effort, and sometimes too much effort. Because of their high cost of syndicating deals, experienced VCs may overestimate the quality of projects, which, together with them being the 
sole investor, induces them to exert too much effort. ${ }^{32}$ The fact that very experienced VCs exert more effort is consistent with Sapienza et al. (1996). This is also in line with Kaplan and Strömberg (2004) who find i) a positive relationship between value-added activities and the equity stake of venture capitalists, and ii) a negative relationship between the size of syndicates and value-added activities. Last, our results stress the fact that whether syndication triggers more effort than standalone investments depends on the level of experience of VCs: in particular, moderately experienced VCs should exert more effort when they form a syndicate.

- Our model allows to discuss whether standalone investments should exhibit more or less variable returns than syndicated investments. Brander et al. (2002) find in their sample that standalone investments have less variable returns. The predictions we can derive from the model are less clearcut, but can shed light on the determinants of the variability of returns of $\mathrm{VC}$ investments. On the one hand, experienced VCs (who invest alone) have more precise signals: their investments should exhibit less variable returns. On the other hand, experienced VCs who find it too costly to syndicate accept too many projects: in that case, their standalone investments should exhibit more variable returns. Our analysis states that highly experienced VCs benefit from the positive precision-of-signal effect, but suffer from relying on their own information only. The investments of less experienced VCs exhibit exactly the opposite features: each piece of information is less precise, but those VCs manage to syndicate, which improves their selection process. Which effect dominates according to the level of experience of VCs is still an empirical issue.

- Last, an important question is whether syndicated projects are more or less profitable than standalone projects. The empirical evidence is mixed. Brander et al. (2002) find a positive relationship between syndication and the return of portfolio firms. But they also find that syndicated investment have higher volatility than stand-alone investments. Hopp and Rieder (2006) document that syndication has a positive effect on sales growth. However they find no significant impact of the number of syndicated members on the sales growth. Using more appropriate performance measures, Hege, Palomino and Schwienbacher (2006) find no significant relationship between the size of the syndicate and the level of excess returns. In our model, the relationship between syndication and expected returns depends on the level of experience of VCs. The important point is that syndicated investments can exhibit higher expected returns than standalone investments. ${ }^{33}$ This result is to be contrasted to the result of Brander et al. (2002). They predict lower expected returns for syndicated projects, when syndication is used

\footnotetext{
${ }^{32}$ Overprovision of effort arises in our model from the assumption that the efficiency of the VC's effort increases with the quality of the project: it is therefore optimal not to exert effort if it is unlikely that the project is good. Note that with constant effort efficiency, experienced VCs who cannot syndicate would invest too much, and also exert too much effort: our predictions would be unchanged, but the current specification allows to disantangle the investment decision from the effort decision.

${ }^{33}$ We provide in the appendix page 33 a numerical example to highlight this point.
} 
for a screening motive. We complement their work by showing that this result depends crucially on the level of experience of VCs.

\section{Comparison with alternative motives of syndication}

Several motives for syndication are traditionally proposed in the literature (although not relying on formal models). One possible reason for syndication is the capital constraint of venture capitalists: some deals may simply be too large to be undertaken by a single VC who might not have enough funds, or might be prevented by his fund's covenants to invest a large amount in a single firm. The argument would imply the following empirical patterns: one should observe that syndication at any given round of investment increases with the size of the deals, and decreases with the size of the venture capital fund. To the extent that early stage rounds involve generally less financial investment than later stage rounds, the capital constraint hypothesis also implies that there is less syndication at earlier stages, and more syndication at later stages. This prediction is exactly the opposite of what our model suggests: when uncertainty is high (earlier stages) there is a greater need to gather information, and VCs' signals are unlikely to be very precise, which should result in more syndicated deals. Some empirical evidence seems to speak against the capital constraint motive as the only reason for syndication. For instance, Hopp and Rieder (2006) report that syndication is not related to the amount of capital under management: large VC funds do not syndicate less than small counterparts. Also, anecdotal evidence on UK venture capital investments suggests that the size of syndicates is smaller at later stages, while amounts invested are larger (Wright and Lockett (2003)). It is plausible though that capital constraints play, in some instances, a role in the decision to syndicate. Our model simply suggests an alternative, and possibly complementary rationale for syndication: while early stage syndication may be due to the need to gather information, later stage syndication may simply reflect some capital constraints of VC funds. Last, the capital constraint argument is agnostic concerning some of the empirical predictions we suggest. If syndication was only a matter of investment size, it is not obvious why this should affect the level of effort of syndicate members (even if each syndicate member has a lower share of equity, the total project value is higher, and effort should not be affected), or their decision of who to syndicate with.

Another reason usually put forward is the risk diversification motive: VCs syndicate deals to invest in more projects, and to hold a more diversified portfolio. We are not aware of any evidence that directly tests this assumption. From a theoretical point of view though, it is not clear why VCs should care about diversification at the fund level, and why syndication should be the tool to mitigate risk. First, limited partners who invest in VC funds are institutional investors who only invest a small portion of their endowments in the venture capital sector, and who can invest in several VC funds. It is not clear why there is also a need to diversify at the fund level from the investors point of view. In addition, if the $\mathrm{VC}$ firms themselves want to 
mitigate risk, they can achieve this through the management of several funds, each dedicated to a specific line of business, or geographic area. It is thus rather uneasy to derive predictions from the risk mitigation motive. Some empirical evidence by Hopp and Rieder (2006) find that the concentration of $\mathrm{VC}$ portfolios increases with syndication. If any, this suggests that syndication is not used to hold a diversified portfolio of firms in different lines of business. While we believe that the risk mitigation motive bears some relevance, it seems unlikely that it is the only determinant of the decision to syndicate. Also, diversification per se cannot explain some usually observed patterns of syndication, in particular the fact that experienced VCs syndicate less, and more likely with their peers.

Last, several models view syndication as an optimal investment arrangement. Building on Lerner (1994)'s idea that syndication can improve the selection process, Brander et al. (2002) propose two alternative models of syndication, relying respectively on information gathering, and on value-added. We use different assumptions, which lead to different predictions. First, we explicitly consider the level of experience in the syndication decision, while they do not. This allows us to derive predictions linking the level of experience, to the syndication decision, to the ex-post involvement of VCs, and to the characteristics of $\mathrm{VC}$ investments in terms of variance and return. We already discussed above to which extent these predictions fit some empirical evidence. Second, by construction in their model, syndicated projects exhibit more value-added from VCs than standalone investments (since it is one reason for syndication). We enrich their analysis by considering simultaneously the selection process and effort decision. This allows us to predict that experienced VCs syndicate less and provide more effort. Such a prediction was not possible in their framework. Cestone, Lerner, and White (2006) have more recently proposed a model of syndication to gather signals. Their assumptions differ from ours on several dimensions. They consider privately observed signals, and investigate the incentive costs of syndication, while we focus on observable signals and explore the potential competition costs of syndication. Our predictions partly differ in the sense that highly experienced VCs in their model do not always prefer to syndicate with experienced counterparts, because of the high incentive costs. In our model, if one $\mathrm{VC}$ wants to syndicate, he always prefers the most experienced partner available. In addition, our analysis of the provision of effort is absent in their model, so that some of our predictions are irrelevant in their analysis. Finally, Bachman and Schindele (2006) motivate syndication as a commitment device not to steal the entrepreneur's idea : in particular, they derive predictions relating the syndication size to the extent of legal protection of ideas, which are different and possibly complementary to ours.

\section{Possible tests of our model}

Some available empirical evidence fits well the implications of our analysis, but could also fit alternative explanations. One way to disentangle our predictions from others is to think about 
more specific tests. For instance, the fact that more mature industries exhibit less syndication could be due to different features. It could be, as we argue, that the precision of the VCs evaluation is larger in those industries. Alternatively, it could be that for some industries (e.g. services), projects require smaller amounts of investment, and VCs do not face hard capital constraints. Also, there could be some heterogeneity in mature industries, with some projects being more innovative and difficult to evaluate. Another way to test our prediction is to measure whether more drastic innovations at the firm level induce more syndication. To test this hypothesis, one could identify the product market strategies of different start-ups, in the spirit of the analysis of Hellmann and Puri (2000), to define groups of firms of different innovativeness. We expect syndication to be more prevalent for the most innovative firms.

In addition, some of our results highlight the importance of the level of experience of VCs for the observed value added, and the financial return of syndicates. The empirical result of Brander et al. (2002) that standalone investments exhibit less variable returns illustrates well the case where VCs are highly experienced. It would be useful to include the level of experience of venture capitalists to create different groups of standalone investments. One should find that the difference in variability between standalone and syndicated investments should be stronger for more experienced VCs. In the same vein, the model predicts that standalone experienced VCs will exert more effort that syndicated less experienced VCs. One could introduce the level of experience of VCs when measuring value-added. Effort should increase with the level of experience of $\mathrm{VCs}$, and should increase for standalone investments. An interesting feature of the model is that there can be overprovision of effort by experienced VCs. This implies that the relationship between effort and financial returns is not monotonic, especially for high levels of experience. Empirically, this means that if one wants to investigate the relationship between effort and returns, one should take into account the level of experience of VCs, on top of the syndication decision.

\section{Conclusion}

In this paper we investigate the efficiency of the selection process of venture capitalists. We provide a rationale for the syndication of venture capital investments based on the trade-off between the need to gather accurate information on the quality of an investment opportunity, and the need to maintain monopoly profits. We consider a model in which two venture capitalists can generate costless signals on a highly uncertain venture. Although gathering information can be profit-enhancing, collecting the second appraisal creates potential competition for the initial venture capitalist. Forming a syndicate is a coordination device that prevents profit-dissipating competition from actually taking place. Such a contract is however costly for the initial venture capitalist, since he must forgo part of the project's surplus. The higher the profits the initial 
venture capitalist can capture when being the sole investor, the more reluctant he is to syndicate. Therefore the actual syndication decision will not induce efficient learning. This is the first cost of syndication. We show that this cost increases with the level of experience of the initial venture capitalist. We then relate the syndication decision to the post-investment involvement of venture capitalists. Very experienced venture capitalists find it too costly to syndicate and do not gather enough information. Relying on their own signal, they provide too much effort. Moderately experienced VCs also find it too costly to syndicate, and do not gather enough information. However, because of their unprecise evaluation, they do not exert enough effort.

A second cost of syndication arises when there is moral hazard on the ex post value-added effort of the initial venture capitalist. Syndication forces the two venture capitalists to share ownership of the firm, which weakens the incentives to exert effort. We establish that this cost decreases with the experience of the initial venture capitalist. Therefore syndication can also be costly for very inexperienced venture capitalists since it can alter their incentives. This results in the underprovision of effort by young or inexperienced venture capitalists.

We derive results concerning the link between the level of experience of venture capitalists, the decision to syndicate, and the intensity of their ex-post involvement. 


\section{Appendix}

\section{Proof of proposition 1}

- To set the proof of proposition 1, we first need to characterize the optimal investment/effort decision when $\mathrm{VC}_{1}$ calls for a second evaluation according to the signals and the levels of experience of the two agents.

Start with the case where $s_{1}=H$.

Suppose first that $s_{2}=H$. With bayesian updating, we get:

$$
q_{H, H}=\frac{\alpha_{1} \alpha_{2} q_{0}}{\alpha_{1} \alpha_{2} q_{0}+\left(1-\alpha_{1}\right)\left(1-\alpha_{2}\right)\left(1-q_{0}\right)} .
$$

Using equation (1), it follows that:

$N P V\left(e, q_{H, H}\right) \geq 0 \Leftrightarrow \alpha_{2} \geq \frac{\left(1-\alpha_{1}\right)\left(1-q_{0}\right)\left(I-p_{l} R+c\right)}{\alpha_{1} q_{0}\left(\left(p_{h}+\epsilon\right) R-I-c\right)+\left(1-\alpha_{1}\right)\left(1-q_{0}\right)\left(I-p_{l} R+c\right)} \equiv \varphi_{I, e}\left(\alpha_{1}\right)$.

And using equation (2):

$$
N P V\left(\not k, q_{H, H}\right) \geq 0 \Leftrightarrow \alpha_{2} \geq \frac{\left(1-\alpha_{1}\right)\left(1-q_{0}\right)\left(I-p_{l} R\right)}{\alpha_{1} q_{0}\left(p_{h} R-I\right)+\left(1-\alpha_{1}\right)\left(1-q_{0}\right)\left(I-p_{l} R\right)} \equiv \varphi_{I, \mathcal{A}}\left(\alpha_{1}\right) .
$$

It follows that:

$$
\begin{aligned}
N P V\left(e, q_{H, H}\right) \geq N P V\left(\not e, q_{H, H}\right) \Leftrightarrow \alpha_{2} & \geq \frac{\left(1-\alpha_{1}\right)\left(1-q_{0}\right) c}{\alpha_{1} q_{0}(\epsilon R-c)+\left(1-\alpha_{1}\right)\left(1-q_{0}\right) c} \\
& \equiv \varphi_{e}\left(\alpha_{1}\right)
\end{aligned}
$$

One checks easily that under assumption $1, \varphi_{e}\left(\alpha_{1}\right) \geq \varphi_{I, e}\left(\alpha_{1}\right) \geq \varphi_{I, \phi}\left(\alpha_{1}\right) \forall \alpha_{1}$. Therefore, when both VCs receive good signals, it is optimal :

- to invest and exert effort when $\alpha_{2}>\varphi_{e}\left(\alpha_{1}\right)$,

- not to invest when $\alpha_{2}<\varphi_{I, d}\left(\alpha_{1}\right)$,

- to invest and not exert effort when $\alpha_{2} \in\left[\varphi_{I, q}\left(\alpha_{1}\right) ; \varphi_{e}\left(\alpha_{1}\right)\right]$.

Suppose next that $s_{2}=L$.

$N P V\left(e, q_{H, L}\right) \geq 0 \Leftrightarrow \alpha_{2} \leq \frac{\alpha_{1} q_{0}\left(\left(p_{h}+\epsilon\right) R-I-c\right)}{\alpha_{1} q_{0}\left(\left(p_{h}+\epsilon\right) R-I-c\right)+\left(1-\alpha_{1}\right)\left(1-q_{0}\right)\left(I-p_{l} R+c\right)} \equiv \varphi_{I /, e}\left(\alpha_{1}\right)$.

And :

$$
N P V\left(\not e, q_{H, L}\right) \geq 0 \Leftrightarrow \alpha_{2} \leq \frac{\alpha_{1} q_{0}\left(p_{h} R-I\right)}{\alpha_{1} q_{0}\left(p_{h} R-I\right)+\left(1-\alpha_{1}\right)\left(1-q_{0}\right)\left(I-p_{l} R\right)} \equiv \varphi_{I, \ell}\left(\alpha_{1}\right) .
$$

It follows that:

$$
\begin{aligned}
N P V\left(e, q_{H, L}\right) \geq N P V\left(\not e, q_{H, L}\right) \Leftrightarrow \alpha_{2} & \leq \frac{\alpha_{1} q_{0}(\epsilon R-c)}{\alpha_{1} q_{0}(\epsilon R-c)+\left(1-\alpha_{1}\right)\left(1-q_{0}\right) c} \\
& \equiv \varphi_{q}\left(\alpha_{1}\right)
\end{aligned}
$$


Under assumption 1, $\varphi_{q}\left(\alpha_{1}\right) \leq \varphi_{\mathbb{Y}, e}\left(\alpha_{1}\right) \leq \varphi_{\mathbb{I}, \ell}\left(\alpha_{1}\right) \forall \alpha_{1}$. Therefore:

- it is optimal to invest and exert effort if $\alpha_{2}<\varphi_{q}\left(\alpha_{1}\right)$,

- it is optimal not to invest if $\alpha_{2}>\varphi_{\mathbb{I}, d}\left(\alpha_{1}\right)$,

- it is optimal to invest but not to exert effort if $\alpha_{2} \in\left[\varphi_{q}\left(\alpha_{1}\right) ; \varphi_{I, q}\left(\alpha_{1}\right)\right]$.

Consider now the case $s_{1}=L$.

If $s_{2}=L$, it is clearly optimal not to invest.

Suppose next that $s_{2}=H$. Proceeding as before, we get:

$N P V\left(e, q_{L, H}\right) \geq 0 \Leftrightarrow \alpha_{2} \geq \frac{\alpha_{1}\left(1-q_{0}\right)\left(I-p_{l} R+c\right)}{\left(1-\alpha_{1}\right) q_{0}\left(\left(p_{h}+\epsilon\right) R-I-c\right)+\alpha_{1}\left(1-q_{0}\right)\left(I-p_{l} R+c\right)} \equiv \nu_{I, e}\left(\alpha_{1}\right)$.

And:

$$
N P V\left(\not e, q_{L, H}\right) \geq 0 \Leftrightarrow \alpha_{2} \geq \frac{\alpha_{1}\left(1-q_{0}\right)\left(I-p_{l} R\right)}{\left(1-\alpha_{1}\right) q_{0}\left(p_{h} R-I\right)+\alpha_{1}\left(1-q_{0}\right)\left(I-p_{l} R\right)} \equiv \nu_{I, \phi}\left(\alpha_{1}\right) .
$$

It follows that:

$$
\begin{aligned}
N P V\left(e, q_{L, H}\right) \geq N P V\left(\not e, q_{L, H}\right) \Leftrightarrow \alpha_{2} & \geq \frac{\alpha_{1}\left(1-q_{0}\right) c}{\left(1-\alpha_{1}\right) q_{0}(\epsilon R-c)+\alpha_{1}\left(1-q_{0}\right) c} \\
& \equiv \nu_{e}\left(\alpha_{1}\right)
\end{aligned}
$$

One checks easily that $\nu_{e}\left(\alpha_{1}\right) \geq \nu_{I, e}\left(\alpha_{1}\right) \geq \nu_{I, \ell}\left(\alpha_{1}\right) \forall \alpha_{1}$. Also, $\nu_{I, \Phi}\left(\alpha_{1}\right)$ is always larger than $\frac{1}{2}$ since $N P V\left(\not \ell, q_{L}\right) \leq 0$. We conclude that:

- when $\alpha_{2}<\nu_{I, \theta}\left(\alpha_{1}\right)$, it is optimal not to invest,

- when $\alpha_{2} \in\left[\nu_{I, \phi}\left(\alpha_{1}\right) ; \nu_{e}\left(\alpha_{1}\right)\right]$, investment takes place, but not effort is exerted,

- when $\alpha_{2}>\nu_{e}\left(\alpha_{1}\right)$, it is optimal to invest and exert effort.

- The second part of the proof consists in determining when the investment decision is reversed for at least one possible signal $s_{2}$.

When $s_{1}=L, \mathrm{VC}_{1}$ does not invest alone. Hence information is valuable when $\mathrm{VC}_{2}$ 's signal makes the project's NPV positive. This arises when $\alpha_{2}>\nu_{I, q}\left(\alpha_{1}\right)$.

Suppose now that $s_{1}=H$. Define $\alpha_{I}$ the minimum level of $\mathrm{VC}_{1}$ 's experience, such that investing but not exerting effort becomes valuable after a good signal. Using equation (2), such a threshold is obtained by solving:

$$
N P V\left(\not \ell, q_{H}\right) \geq 0 \Leftrightarrow \alpha_{1} \geq \frac{\left(1-q_{0}\right)\left(I-p_{l} R\right)}{q_{0}\left(p_{h} R-I\right)+\left(1-q_{0}\right)\left(I-p_{l} R\right)} \equiv \alpha_{I} .
$$

Define similarly $\alpha_{e}$ the minimum level of experience above which it is valuable to start exerting effort. This threshold solves:

$$
N P V\left(e, q_{H}\right) \geq N P V\left(\not e, q_{H}\right) \Leftrightarrow \alpha_{1} \geq \frac{\left(1-q_{0}\right) c}{q_{0}(\epsilon R-c)+\left(1-q_{0}\right) c} \equiv \alpha_{e} .
$$


See that:

$$
\alpha_{e} \geq \alpha_{I} \quad \Leftrightarrow \quad c\left(p_{h}-p_{l}\right) \geq \epsilon\left(I-p_{l} R\right) .
$$

As a consequence, under assumption 1, after receiving a good signal, it is optimal not to invest when $\alpha_{1}<\alpha_{I}$, to invest and not exert effort when $\alpha_{1} \in\left[\alpha_{I} ; \alpha_{e}\right]$, and to invest and exert effort when $\alpha_{1}>\alpha_{e}$.

It follows that :

- when $\alpha_{1}<\alpha_{I}, \mathrm{VC}_{1}$ asks for a second evaluation if $\mathrm{VC}_{2}$ 's good signal makes the project's NPV positive, i.e. when $\alpha_{2}>\varphi_{I, q}\left(\alpha_{1}\right)$.

- When $\alpha_{1} \in\left[\alpha_{I} ; \alpha_{e}\right], \mathrm{VC}_{1}$ calls for $\mathrm{VC}_{2}$ if the latter is experienced enough to deter investment when receiving a bad signal, or to induce effort. Since $\varphi_{e}\left(\alpha_{1}\right)>\varphi_{\mathbb{H}, q}\left(\alpha_{1}\right)$ for all $\alpha_{1}$ in the interval considered, information gathering occurs when $\alpha_{2}>\varphi_{\mathbb{I}, \ell}\left(\alpha_{1}\right)$.

- When $\alpha_{1}>\alpha_{e}$, information gathering occurs to deter effort after a bad signal $s_{2}$, or to deter investment, i.e. when $\left.\alpha_{2}>\min \left[\varphi_{q}\left(\alpha_{1}\right) ; \varphi_{\mathbb{H}, \ell}\left(\alpha_{1}\right)\right)\right]$.

Last, check that $\frac{\partial \varphi_{I, q}\left(\alpha_{1}\right)}{\partial \alpha_{1}}$ is negative so that the minimum level of $\mathrm{VC}_{2}$ 's experience needed to trigger investment decreases with $\alpha_{1}$. At the opposite note that $\frac{\partial \varphi_{Y, q}\left(\alpha_{1}\right)}{\partial \alpha_{1}}$ is positive, which means that the minimum level of $\mathrm{VC}_{2}$ 's experience needed to deter investment increases with $\alpha_{1}$. Similarly, $\frac{\partial \varphi_{e}\left(\alpha_{1}\right)}{\partial \alpha_{1}} \leq 0$ and $\frac{\partial \varphi_{\ell}\left(\alpha_{1}\right)}{\partial \alpha_{1}} \geq 0$, so that the same result applies concerning the effort decision.

\section{Generalization with a continuous investment model}

We consider a continuous investment model to assess the robustness of our results. To give a flavor of the generalization of our model, we present here the results of proposition 1, with a general investment model, for the case of an initial good signal (i.e. $s_{1}=H$ ).

Consider the following continuous investment model.

For any investment level $I \in \mathbb{R}^{+}$, the project generates in case of success a revenue $R(I)$. The function $R$ on $\mathbb{R}^{+}$is such that: $R^{\prime}(I)>0$, and $R^{\prime \prime}(I)<0$. The FOC of the maximization of the project's NPV when effort is not exerted gives:

$$
R^{\prime}(I)=\frac{1}{q\left(p_{h}-p_{l}\right)+p_{l}} .
$$

Denote $I_{q}(q)$ the solution of equation (4). Since we have decreasing returns ( $R$ is concave), $I_{q}(q)$ is an increasing function of the belief $q$. When investment occurs, the project's NPV can be written:

$$
-I_{q}(q)+\left[q\left(p_{h}-p_{l}\right)+p_{l}\right] R\left(I_{q}(q)\right) .
$$


Define $q_{I, q}^{*}$ the belief such that the project's NPV, when effort is not exerted, is equal to zero. The belief $q_{I, q}^{*}$ verifies:

$$
-I_{q}\left(q_{I, q}^{*}\right)+\left[q_{I, \Phi}^{*}\left(p_{h}-p_{l}\right)+p_{l}\right] R\left(I_{q}\left(q_{I, \ell}^{*}\right)\right)=0 .
$$

Note that in the binary investment choice model, we are able to specify explicitly $q_{I, q}^{*}$ and $I_{q}(q)$, thus to solve analytically the model. Also, we can easily present the solutions graphically in a two-dimension space. All this is not possible in the general continuous investment model.

This gives the following investment rule, where $I_{d}^{*}$ is the optimal level of investment, given that no effort is exerted:

$$
\left\{\begin{array}{lll}
I_{\phi}^{*}=0 & \text { if } \quad q<q_{I, \phi}^{*} \\
I_{\not d}^{*}=I_{\phi}(q) & \text { if } \quad q \geq q_{I, \phi}^{*}
\end{array}\right.
$$

Similarly, the FOC of the maximization of the NPV when effort is exerted is:

$$
R^{\prime}(I)=\frac{1}{q\left(p_{h}+\epsilon-p_{l}\right)+p_{l}} .
$$

Denote $I_{e}(q)$ the solution of equation (5) and define $q_{I, e}^{*}$ the belief such that the project's NPV, when effort is exerted, is equal to zero. The belief $q_{I, e}^{*}$ verifies:

$$
-c-I_{e}\left(q_{I, e}^{*}\right)+\left[q_{I, e}^{*}\left(p_{h}+\epsilon-p_{l}\right)+p_{l}\right] R\left(I_{e}\left(q_{I, e}^{*}\right)\right)=0 .
$$

The optimal level of investment, given that no effort is exerted, is defined by:

$$
\left\{\begin{array}{lll}
I_{e}^{*}=0 & \text { if } \quad q<q_{I, e}^{*} \\
I_{e}^{*}=I_{e}(q) & \text { if } \quad q \geq q_{I, e}^{*}
\end{array}\right.
$$

We consider that effort is not very efficient, $q_{I, \ell}^{*}<q_{I, e}^{*}$, which is equivalent to the following condition:

$$
\frac{\frac{I_{q}^{*}}{R\left(I_{q}^{*}\right)}-p_{l}}{p_{h}-p_{l}}<\frac{\frac{c+I_{e}^{*}}{R\left(I_{e}^{*}\right)}-p_{l}}{p_{h}+\epsilon-p_{l}}
$$

In our binary investment model, the inequality (6) boils down to what is referred to as assumption (1).

Define $q_{e}^{*}$ the minimum level of experience above which it is valuable to start exerting effort. This threshold solves:

$$
N P V\left(e, q_{H}\right) \geq N P V\left(\not e, q_{H}\right) \Leftrightarrow q_{e}^{*} \geq \frac{I_{e}^{*}+c-I_{q}^{*}+p_{l}\left(R\left(I_{q}^{*}\right)-R\left(I_{e}^{*}\right)\right)}{\left(p_{h}+\epsilon-p_{l}\right) R\left(I_{e}^{*}\right)-\left(p_{h}-p_{l}\right) R\left(I_{q}^{*}\right)} .
$$


Check that under condition (6), we have that $q_{I, \phi^{*}}^{*}<q_{e}^{*}$.

Initially, $q_{0}<q_{I, q_{q}^{*}}^{*}$ the project is not profitable. Suppose first that $\mathrm{VC}_{1}$ has received a good signal, but is not experienced enough to invest alone, i.e. $q_{H}<q_{I, q^{*}}^{*}$ He asks for a second evaluation if the project's NPV becomes positive if $\mathrm{VC}_{2}$ receives a good signal, i.e. if:

$$
\begin{aligned}
N P V\left(\not e, q_{H, H}\right) \geq 0 & \Leftrightarrow q_{H, H} \geq q_{\phi}^{*} \\
& \Leftrightarrow \alpha_{2} \geq \frac{q_{q}^{*}\left(1-\alpha_{1}\right)\left(1-q_{0}\right)}{\alpha_{1} q_{0}\left(1-q_{\phi}^{*}\right)+q_{\phi}^{*}\left(1-\alpha_{1}\right)\left(1-q_{0}\right)} \equiv \varphi_{R(I), \phi}\left(\alpha_{1}\right)
\end{aligned}
$$

Assume now that investing but not exerting effort becomes valuable after a good signal, i.e. $q_{I, \notin}^{*}<q_{H}<q_{e}^{*}$. $\mathrm{VC}_{1}$ asks for a second evaluation if $\mathrm{VC}_{2}$ is experienced enough to induce effort when receiving a good signal or to deter investment when receiving a bad signal i.e. if:

$$
\begin{aligned}
N P V\left(e, q_{H, H}\right) \geq N P V\left(\not e, q_{H, H}\right) & \Leftrightarrow q_{H, H} \geq q_{e}^{*} \\
& \Leftrightarrow \alpha_{2} \geq \frac{\left(1-\alpha_{1}\right)\left(1-q_{0}\right) q_{e}^{*}}{\alpha_{1} q_{0}\left(1-q_{e}^{*}\right)-\left(1-\alpha_{1}\right)\left(1-q_{0}\right) q_{e}^{*}} \equiv \varphi_{e}\left(\alpha_{1}\right)
\end{aligned}
$$

or

$$
\begin{aligned}
N P V\left(\not e, q_{H, L}\right) \leq 0 & \Leftrightarrow q_{H, L} \leq q_{I, \phi}^{*} \\
& \Leftrightarrow \alpha_{2} \geq \frac{\alpha_{1} q_{0}\left(1-q_{q}^{*}\right)}{\alpha_{1} q_{0}\left(1-q_{q}^{*}\right)+q_{q}^{*}\left(1-\alpha_{1}\right)\left(1-q_{0}\right)} \equiv \varphi_{R,(I), \phi}\left(\alpha_{1}\right)
\end{aligned}
$$

To state the results of proposition 1 , check that functions $\varphi_{R(I), A}\left(\alpha_{1}\right), \varphi_{e}\left(\alpha_{1}\right)$ and $\varphi_{R(I), \mathcal{A}}\left(\alpha_{1}\right)$ have the same properties as in the binary investment model. See that:

$$
\frac{\partial \varphi_{R(I), \phi}\left(\alpha_{1}\right)}{\partial \alpha_{1}}<0
$$

This implies that the minimum level of $\mathrm{VC}_{2}$ 's experience needed to trigger investment decreases with $\alpha_{1}$.

We have that

$$
\frac{\partial \varphi_{e}\left(\alpha_{1}\right)}{\partial \alpha_{1}}<0
$$

so that the minimum level of $\mathrm{VC}_{2}$ 's experience needed to induce effort decreases with $\alpha_{1}$.

Also:

$$
\frac{\partial \varphi_{R(I), \theta}\left(\alpha_{1}\right)}{\partial \alpha_{1}}>0 .
$$

The minimum level of $\mathrm{VC}_{2}$ 's experience needed to discourage investment increases with $\alpha_{1}$. 


\section{Proof of proposition 2}

The proof of this proposition is straightforward. Recall from the proof of proposition 1 that if $s_{1}=L$ or if $s_{1}=H$ and $\alpha_{1}<\alpha_{I}$, the optimal decision is not to invest. Hence, $\mathrm{VC}_{1}$ decides to syndicate iff:

$$
\begin{aligned}
0<\operatorname{prob}\left(s_{2}=H\right) \frac{1}{2} \max \{0 ; & \left.N P V\left(e, q_{s_{1}, H}\right) ; N P V\left(\not e, q_{s_{1}, H}\right)\right\} \\
& +\operatorname{prob}\left(s_{2}=L\right) \frac{1}{2} \max \left\{0 ; N P V\left(e, q_{s_{1}, L}\right) ; N P V\left(\not e, q_{s_{1}, L}\right)\right\} .
\end{aligned}
$$

Simplifying both sides by $\frac{1}{2}$ gives the same condition for syndication as in the first best.

\section{Proof of proposition 3}

Suppose that $s_{1}=H$. The case where $\alpha_{1}<\alpha_{I}$ is treated in proposition 2 .

- When $\alpha_{1} \in\left[\alpha_{I}, \alpha_{e}\right]$, it is optimal for $\mathrm{VC}_{1}$ to invest but not to exert effort when staying alone. Therefore, $\mathrm{VC}_{1}$ syndicates iff:

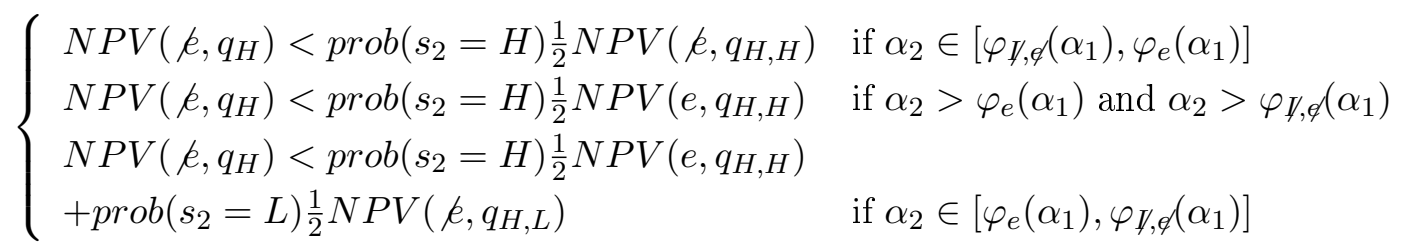

This reduces to

$$
\begin{cases}\alpha_{2}>\frac{2 \alpha_{1} q_{0}\left(p_{h} R-I\right)+\left(1-\alpha_{1}\right)\left(1-q_{0}\right)\left(p_{l} R-I\right)}{\alpha_{1} q_{0}\left(p_{h} R-I\right)-\left(1-\alpha_{1}\right)\left(1-q_{0}\right)\left(p_{l} R-I\right)} \equiv \varphi_{s, I, \ell}\left(\alpha_{1}\right) & \text { if } \alpha_{2} \in\left[\varphi_{\mathbb{I}, \ell}\left(\alpha_{1}\right), \varphi_{e}\left(\alpha_{1}\right)\right] \\ \alpha_{2}>\frac{2 \alpha_{1} q_{0}\left(p_{h} R-I\right)+\left(1-\alpha_{1}\right)\left(1-q_{0}\right)\left(p_{l} R-I+c\right)}{\alpha_{1} q_{0}\left[\left(p_{h}+\epsilon\right) R-I-c\right]-\left(1-\alpha_{1}\right)(1-q)\left(p_{l} R-I-c\right)} \equiv \varphi_{s, I, e}\left(\alpha_{1}\right) & \text { if } \alpha_{2}>\varphi_{e}\left(\alpha_{1}\right) \text { and } \alpha_{2}>\varphi_{I, \ell}\left(\alpha_{1}\right) \\ \alpha_{2}>\frac{\alpha_{1} q_{0}\left(p_{h} R-I\right)+\left(1-\alpha_{1}\right)\left(1-q_{0}\right)\left(p_{l} R-I+c\right)}{\alpha_{1} q_{0}(\epsilon R-c)+\left(1-\alpha_{1}\right)\left(1-q_{0}\right)(c)} \equiv \varphi_{s, e}\left(\alpha_{1}\right) & \text { if } \alpha_{2} \in\left[\varphi_{e}\left(\alpha_{1}\right), \varphi_{I, \ell}\left(\alpha_{1}\right)\right]\end{cases}
$$

The proof of proposition 1 states that information gathering is optimal for $\alpha_{2} \geq \varphi_{\mathbb{J}, \phi}\left(\alpha_{1}\right)$, when $\alpha_{1} \in\left[\alpha_{I}, \alpha_{e}\right]$. It is easy to check that both $\varphi_{s, \mathbb{Z}, \theta}\left(\alpha_{1}\right)$ and $\varphi_{s, \mathbb{Z}, e}\left(\alpha_{1}\right)$ are greater than $\varphi_{\mathbb{I}, e}\left(\alpha_{1}\right) \forall \alpha_{1}$. Also note that $\varphi_{s, e}\left(\alpha_{1}\right)<1$ is not consistent with $\alpha_{1} \geq \alpha_{I}$. Therefore, when $\alpha_{1} \in\left[\alpha_{I}, \alpha_{e}\right]$, potential competition makes $\mathrm{VC}_{1}$ more demanding in term of $\mathrm{VC}_{2}$ 's experience.

For consistency, we verify below whether the necessary conditions for syndication are compatible with the interval considered for $\alpha_{1}$ and $\alpha_{2}$. We have $\varphi_{s, \zeta, A}\left(\alpha_{1}\right) \leq 1$ iff:

$$
\alpha_{1} \leq \frac{2\left(1-q_{0}\right)\left(I-p_{l} R\right)}{q_{0}\left(p_{h} R-I\right)+2\left(1-q_{0}\right)\left(I-p_{l} R\right)}<1 .
$$


which is compatible with some $\alpha_{1} \in\left[\alpha_{I}, \alpha_{e}\right]$.

And $\varphi_{s, \not, e}\left(\alpha_{1}\right) \leq 1$ iff:

$$
\alpha_{1} \leq \frac{2\left(1-q_{0}\right)\left(I-p_{l} R\right)}{q_{0}\left(p_{h} R-I\right)-q_{0}(\epsilon R-c)+2\left(1-q_{0}\right)\left(I-p_{l} R\right)}<1 .
$$

which is compatible with $\alpha_{1} \geq \alpha_{I}$.

- When $\alpha_{1}>\alpha_{e}$, it is optimal for $\mathrm{VC}_{1}$ to invest and exert effort when staying alone. $\mathrm{VC}_{1}$ syndicates iff:

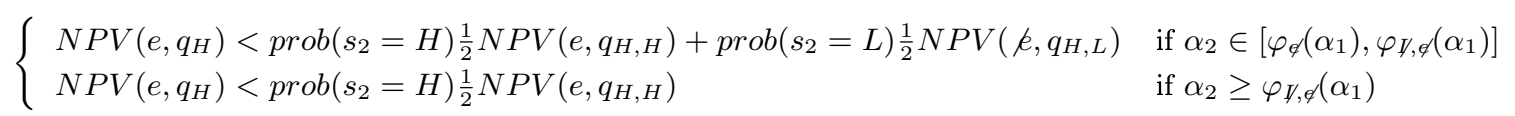

This equation simplifies to:

$$
\begin{cases}\alpha_{2}>\frac{\alpha_{1} q_{0}\left[\left(p_{h}+\epsilon\right) R-I-c\right]+\left(1-\alpha_{1}\right)\left(1-q_{0}\right)\left(p_{l} R-I-c\right)+\alpha_{1} q_{0}(\epsilon R-c)}{\alpha_{1}\left(p_{0}(\epsilon-c)+\left(1-\alpha_{1}\right)\left(1-q_{0}\right) c\right.} \equiv \varphi_{s, I, \ell}\left(\alpha_{1}\right) & \text { if } \alpha_{2} \in\left[\varphi_{\phi}\left(\alpha_{1}\right), \varphi_{I, \ell}\left(\alpha_{1}\right)\right] \\ \alpha_{2}>\frac{2 \alpha_{1} q_{0}\left(p_{h} R-I\right)+\left(1-\alpha_{1}\right)\left(1-q_{0}\right)\left(p_{l} R-I+c\right)}{\left.\alpha_{1} q_{0}\left[\left(p_{h}+\epsilon\right) R-I-c\right]-\left(1-\alpha_{1}\right)\left(1-q_{0}\right)\left(p_{l} R-I-c\right)\right]} \equiv \varphi_{s, I}\left(\alpha_{1}\right) & \text { if } \alpha_{2}>\varphi_{I, \ell}\left(\alpha_{1}\right)\end{cases}
$$

Simple computations establish that:

- $\varphi_{s, I, \ell}\left(\alpha_{1}\right)>\varphi_{\mathbb{I}, \ell}\left(\alpha_{1}\right)$ : the first case considered does not exist,

- and $\varphi_{s, I}\left(\alpha_{1}\right)<1$ is not compatible with $\alpha_{2} \geq \varphi_{\mathbb{H}, \phi}\left(\alpha_{1}\right)$.

This implies that when $\alpha_{1} \geq \alpha_{e}, \mathrm{VC}_{1}$ prefers not to syndicate.

\section{Proof of corollary 1}

We know from proposition 2 that if $\mathrm{VC}_{1}$ receives a bad signal, or if he receives a good signal but $\alpha_{1}<\alpha_{I}$, he syndicates whenever it is optimal to do so. We thus focus on the case where $s_{1}=H$ and $\alpha_{1} \geq \alpha_{I}$. In that case, the second piece of information is used to deter investment, or to modify the effort decision. Combining the results of propositions 1 and 3, we get:

- if $\alpha_{1} \in\left[\alpha_{I} ; \alpha_{e}\right]$, there is too much investment for $\alpha_{2} \in\left[\varphi_{I, \ell}\left(\alpha_{1}\right) ; \min \left[\varphi_{s, \mathbb{Z}, \ell}\left(\alpha_{1}\right) ; \varphi_{s, \ell, e}\left(\alpha_{1}\right)\right]\right]$,

- if $\alpha_{1}>\alpha_{e}$, there is too much investment for $\alpha_{2}>\varphi_{I, \phi}$.

\section{Proof of corollary 2}

- Suppose that $\alpha_{1} \in\left[\alpha_{I}, \alpha_{e}\right]$

When $\alpha_{2} \in\left[\varphi_{e}\left(\alpha_{1}\right) ; \varphi_{s, I, e}\left(\alpha_{1}\right)\right] \mathrm{VC}_{1}$ invests alone and does not exert effort while a second good signal would encourage effort. There is thus underprovision of effort. 
- Suppose that $\alpha_{1} \geq \alpha_{e}$

Because of the cost of syndication, $\mathrm{VC}_{1}$ prefers not to syndicate, and exerts effort each time he receives a good signal. The first best information gathering requires to ask for a second signal, and stop exerting effort when a bad second signal if obtained, if $\alpha_{2} \in\left[\varphi_{\phi}, \varphi_{I, A}\right]$. There is thus overprovision of effort.

\section{A numerical example of the incidence of the unobservability of effort}

Consider the following parameter values, which are consistent with assumption 1.

$$
q_{0}=0.4 \quad p_{l}=0.3 \quad p_{h}=0.7 \quad R=90 \quad I=50 \quad \epsilon=0.1 \quad c=8
$$

Unobservable effort does not modify the effort decision under syndication iff

$$
\frac{c}{q_{H, H} \epsilon R} \leq \frac{\left(\frac{1}{2} N P V\left(e, q_{H, H}\right)+I+c\right)}{q_{H, H}\left(p_{h}+\epsilon\right) R+\left(1-q_{H, H}\right) p_{l} R} .
$$

Assume equality and call $\alpha_{2}^{*}\left(\alpha_{1}\right)$ the positive root of the above equation. Thus, the inequality is true if $\alpha_{2} \geq \alpha_{2}^{*}\left(\alpha_{1}\right)$.

The following figure plots the root $\alpha_{2}^{*}\left(\alpha_{1}\right)$ on figure 2 which represents the syndication and effort decision. The dashed region represents the cost of syndication due to unobservable effort. In this zone, when effort is observable, $\mathrm{VC}_{1}$ syndicates and exerts effort when both signals are good. When effort is not observable, $\mathrm{VC}_{1}$ syndicates but does not exert effort when both signals are good: as stated in proposition 4 , moral hazard leads to underprovision of effort when $\mathrm{VC}_{1}$ is not very experienced.

\section{Expected value of syndicated vs standalone projects: a numerical example}

Consider the following parameter values:

$$
q_{0}=0.4 \quad p_{l}=0.3 \quad p_{h}=0.7 \quad R=90 \quad I=45 \quad \epsilon=0.1 \quad c=8
$$

Under these values, assumption 1 holds.

Suppose that there are two VCs in the economy, with experience $\alpha=0.73585$ and $\alpha=0.65$. Note that: 0.73585 and $0.65 \in\left[\alpha_{I}, \alpha_{e}\right], 0.65 \leq \varphi_{I, \ell}(0.73585)$, but $0.73585>\varphi_{I, A}(0.65)$. Also, $0.73585<\nu_{I, q}(0.65)$ and $0.65 \leq \nu_{I, \phi}(0.73585)$. These parameter values imply that: 


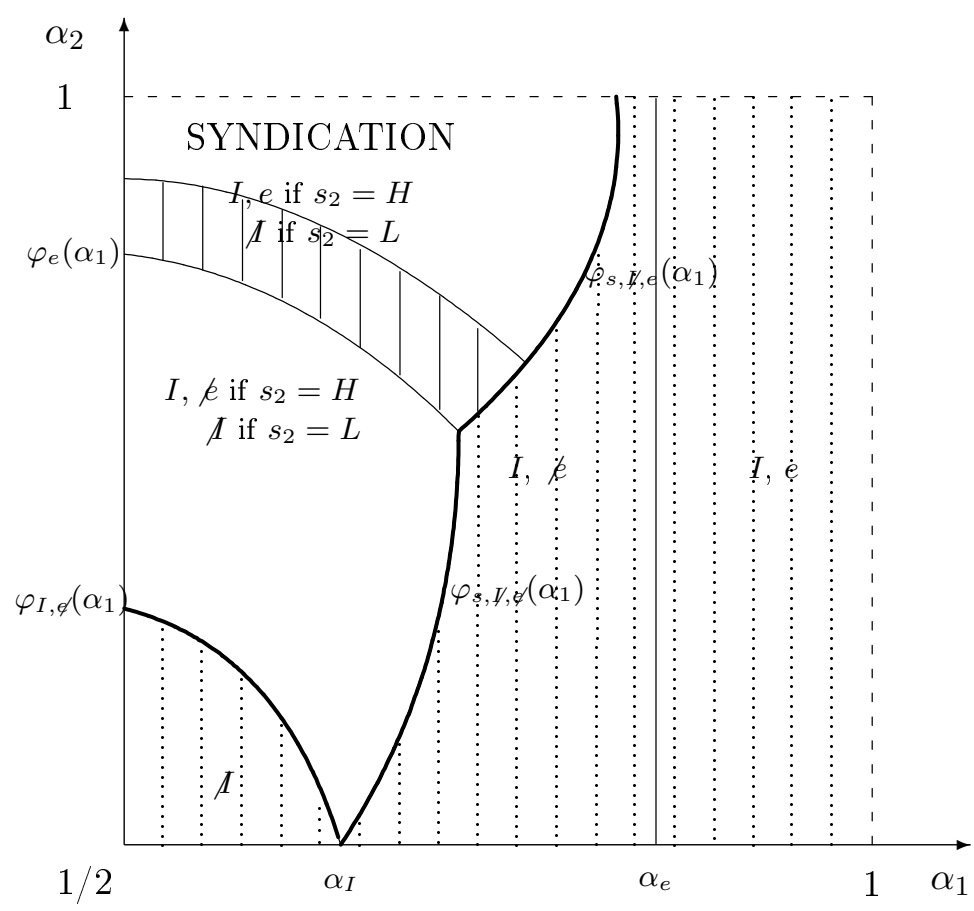

Figure 3: Unobservable effort and syndication decision when $s_{1}=H$.

- if the more experienced VC receives the project first, he prefers not to call for a second signal: he invests alone, and does not exert effort, after a good signal,

- if the less experienced VC receives the project first, he calls for the second signal.

Therefore, we can compute the expected value of the project financed by the more experienced $\mathrm{VC}$, and compare it to the value of the project financed by the syndicate. We get:

$$
\begin{gathered}
N P V\left(e, q_{H}, \alpha_{1}=0.73585\right)=5.4 \\
N P V\left(e, q_{H, H}, \alpha_{1}=0.65, \alpha_{2}=0.73585\right)=9.9083
\end{gathered}
$$

For these parameter values, the standalone project has a lower expected return than the syndicated project. $^{34}$

With potential competition, the less experienced VC still prefers to syndicate: $0.73585>$ $\varphi_{s, I, A}(0.65)$, and invests iff both have received a good signal. The more experienced VC prefers to stay alone and invests only after a good signal.

\footnotetext{
${ }^{34}$ Note however that the more experienced VC earns higher expected profits than the syndicate because he finances more projects (or to put it differently, he finances the project more often).
} 


\section{References}

Admati, Anat, and Paul Pfleiderer, 1994, Robust financial contracting and the role of venture capitalists, Journal of Finance 49, 371-402.

Bachman, Ralph, and Ibolya Schindele, 2006, Theft and syndication in venture capital finance, mime Norwegian School of Management.

Bain, Joe, 1956, Barriers to new competition, Cambridge, Massachussets: Harvard University Press.

Baron, David, and David Besanko, 1999, Informational alliances, Review of Economic Studies 66, 743-768.

Bergemann Dick, and Ulrich Hege, 1998, Venture capital financing, moral hazard, and learning, Journal of Banking and Finance 22, 703-735.

Biais Bruno, and Enrico Perotti, 2003, Entrepreneurs and new ideas, mimeo University of Toulouse and University of Amsterdam.

Brander, James, Raphael Amit, and Werner Antweiler, 2002, Venture-Capital syndication: improved venture selection vs. the value-added hypothesis, Journal of Economics and Management Strategy 11, 423-452.

Bubna, Amit, 2002, Syndication among venture capitalists: when and with whom, Research in Finance 19, 285-321.

Bygrave, William, 1987, Syndicated investments by venture capital firms: a networking perspective, Journal for Business Venturing 2, pp. 139-154.

Bygrave, William, 1988, The structure of the investment networks of venture capital firms, Journal for Business Venturing 3, pp. 137-157.

Bygrave, William, and Jeffry Timmons, 1992, Venture Capital at the Crossroads, Harvard Business School Press, Boston, MA.

Casamatta, Catherine, 2003, Financing and advising: optimal financial contracts with venture capitalists, Journal of Finance 58, 2059-2086.

Casamatta, Catherine, and Carole Haritchabalet, 2006, Competition between Informed Venture Capitalists for the Financing of Entrepreneurs, mimeo.

Cestone, Giacinta, 2002, Venture capital meets contract theory: risky claims or formal control?, CEPR Discussion Paper No. 3462.

Cestone, Giacinta, Josh Lerner, and Lucy White, 2006, The Design of syndicates in venture 
capital, mimeo CSEF-University of Salerno.

Chan, Yuk-Shee, Daniel Siegel, and Anjan Thakor, 1990, Learning, corporate control, and performance requirements in venture capital contracts, International Economic Review 31, p. 365-381.

Chiplin, Brian and Mike Wright, 1997, The syndication of venture capital deals: buy-outs and buy-ins, Frontiers of Entrepreneurship Research, 551-565.

Cornelli, Francesca, and Oved Yosha, 2003, Stage financing and the role of convertible securities, Review of Economic Studies 70, 1-32.

Dessì, Roberta, 2005, Start-up finance, monitoring and collusion, RAND Journal of Economics $36,255-274$.

Dixit, Alan, 1979, A model of duopoly suggesting a theory of entry barriers, Bell Journal of Economics 10, 20-32.

Faure-Grimaud, Antoine, Lucia Quesada, and Eloic Peyrache, 2005, The ownership of ratings, mimeo LSE.

Fenn, George, Nellie Liang, and Stephen Prowse, 1995, The economics of the private equity market, Washington board of Governors of the Federal Reserve System, Staff Study 168.

Garmaise, Mark, 2006, Informed investors and the financing of entrepreneurial projects, mimeo GSB Chicago.

Gerardi, Dino, Richard MacLean, and Andrew Postlewaite, 2005, Aggregation of expert opinions, Cowles Foundation DP 1503.

Gompers, Paul, 1995, Optimal investment, monitoring, and the staging of venture capital, Journal of Finance 50, 1461- 1489.

Gompers, Paul, and Josh Lerner, 1996, The use of covenants: An empirical analysis of venture partnership agreements, Journal of Law and Economics 39, 463-498.

Gompers, Paul, and Josh Lerner, 1999, The Venture Capital Cycle, MIT Press.

Gorman, Michael, and William Sahlman, 1989, What do venture capitalists do?, Journal of Business Venturing 4, 231- 248.

Gromb, Denis, and David Martimort, 2004, The organization of delegated expertise, CEPR DP 4572.

Hege, Ulrich, Frédéric Palomino, and Armin Schwienbacher, 2006, Venture capital performance in Europe and the United States: a comparative analysis, mimeo HEC.

Hellmann, Thomas, 1998, The allocation of control rights in venture capital contracts, Rand 
Journal of Economics 29, 57-76.

Hellmann, Thomas, and Manju Puri, 2002, Venture capital and the professionalization of start-up firms: Empirical evidence, Journal of Finance 57, 169-197.

Hopp, Christian, and Finn Rieder, 2006, What drives venture capital syndication?, mimeo University of Konstanz.

Kaplan, Steve, and Per Strömberg, 2003, Financial contracting theory meets the real world: an empirical analysis of venture capital contracts, Review of Economic Studies 70, 281-315.

Kaplan, Steven, and Per Strömberg, 2004, Characteristics, contracts, and actions: Evidence from venture capitalist analyses, Journal of Finance 59, 2177-2210.

Lerner, Josh, 1994, The syndication of venture capital investments, Financial Management 23, $16-27$.

Lerner, Josh, 1995, Venture capitalists and the oversight of private firms, Journal of Finance 50, 301-318.

Lizzeri, Alessandro, 1999, Information revelation and certification intermediaries, RAND Journal of Economics 30, 214-231.

Lockett, Andy, and Mike Wright, 2001, The syndication of venture capital investments, Omega $29,375-390$.

Morrison, Alan, and Lucy White, 2004, Financial liberalisation and capital regulation in open economies, Oxford Financial research Centre WP.

Pichler, Pegaret, and William Wilhelm, 2001, A theory of the syndicate: Form follows function, Journal of Finance 56, 2237-2264.

Renucci, Antoine, 2000, Optimal claims and tightness of relationships with a value-enhancing investor, mimeo University of Toulouse.

Repullo, Rafael, and Javier Suarez, 1999, Venture capital finance: a security design approach, CEPR Discussion Paper No. 2097.

Sahlman, William, 1988, Aspects of financial contracting in venture capital, Journal of Applied Corporate Finance 1, 23-36.

Sahlman, William, 1990, The structure and governance of venture capital organizations, Journal of Financial Economics 27, 473-522.

Sapienza, Harry, Sophie Manigart, and Wim Vermeir, 1996, Venture capitalist governance and value-added in four countries, Journal of Business Venturing 11, 439-469. 
Schmidt, Klaus, 2003, Convertible securities and venture capital finance, Journal of Finance 58, 1139-1166.

Spence, Michael, 1977, Entry, capacity investment and oligopolistic pricing, Bell Journal of Economics 8, 534-544.

Wright, Mike, and Andy Lockett, 2003, The structure and management of alliances: syndication in the venture capital industry, Journal of Management Studies 40, 2073-2102. 